\title{
El deslizamiento de ladera de noviembre 2007 y generación de una presa natural en el río Grijalva, Chiapas, México
}

\author{
Alejandro Hinojosa-Corona ${ }^{1, *}$, Víctor Manuel Rodríguez-Moreno ${ }^{2}$, Luis Munguía- \\ Orozco $^{3}$ y Octavio Meillón-Menchaca ${ }^{1}$
}

\author{
${ }^{1}$ Depto. Geología, División de Ciencias de la Tierra, CICESE, Carret. Ensenada-Tijuana No. 3918, Zona Playitas, \\ Ensenada, 22860, B.C., México \\ ${ }^{2}$ Campo Experimental Pabellón, INIFAP, Km. 32.5 Carret. Ags-Zac, Pabellón de Arteaga, 20660, Ags., México. \\ ${ }^{3}$ Depto. Sismología, División de Ciencias de la Tierra, CICESE, Carret. Ensenada-Tijuana No. 3918, Zona Playitas, \\ Ensenada, 22860, B.C., México \\ *alhinc@cicese.mx
}

\begin{abstract}
Resumen
La noche del 4 de noviembre de 2007 un deslizamiento de ladera con una extensión de 80 hectáreas que acarreó 48 millones de metros cúbicos de roca y suelo, formó una presa natural que interrumpió el cauce natural del río Grijalva, uno de los más caudalosos de México. El tapón de $80 \mathrm{~m}$ de alto, $800 \mathrm{~m}$ de largo y $300 \mathrm{~m}$ de ancho, se emplazó entre las presas Peñitas (aguas abajo) y Malpaso (aguas arriba). La localidad de San Juan de Grijalva, ubicada en la margen derecha del río, fue afectada por el movimiento en bloque del terreno y por la inundación repentina de una gran ola producto del deslizamiento, los cuales resultaron en la muerte de 25 de sus habitantes. Con apoyo en herramientas de sistemas de información geográfica y teledetección, se presentan el deslizamiento y la cuenca del río Grijalva en el contexto del bloqueo natural de su caudal así como las condiciones anómalas de precipitación durante octubre y principios de noviembre de 2007. Se muestra una perspectiva antes y después del evento mediante modelos digitales del terreno e imágenes satelitales de alta resolución espacial. El modelo digital del terreno posterior al deslizamiento fue generado a partir un levantamiento Lidar aerotransportado. Con estos insumos se construyeron pares estereoscópicos sintéticos, uno previo al deslizamiento, para la fotointerpretación de lineamientos, y uno posterior, para la visualización del fenómeno. Se seleccionaron perfiles topográficos a través de los modelos de antes y después del deslizamiento que, graficados uno junto al otro muestran la magnitud de la remoción de masa. A la superficie planar de ruptura se le estimó una pendiente general de 28 \% con azimut de 239 grados. Se analizan diferentes factores que pudieron inducir el deslizamiento sin encontrar alguno al que se le pueda adjudicar, por lo cual creemos que el causal fue una suma de factores con efectos retardados de unos pocos días.
\end{abstract}

Palabras clave: Río Grijalva, deslizamientos de ladera, teledetección, Lidar, modelo digital de elevación, generación de presa natural

\begin{abstract}
On the night of November $4^{\text {th }} 2007$ a landslide of 48 million cubic meters of rocks and mud with an extension of 80 ha produced a natural barrier to the Grijalva River, one of the largest in Mexico, obstructing its natural flow between the Peñitas (downstream) and Malpaso (upstream) dams and forming a natural barricade $80 \mathrm{~m}$ high, $800 \mathrm{~m}$ long and $300 \mathrm{~m}$ wide. The rural town of San Juan de Grijalva, located on the shoreline of the river, was affected by the moving block and the sudden flooding of a wave generated by the landslide. A death toll of 25 was reported. Assisted with remote sensing and geographic information systems tools, we present the landslide and the Grijalva River watershed in the context of the natural dam and abnormal precipitation during late October and early November 2007. Through high resolution satellite imagery and digital elevation models, a pre-and post-landslide perspective is presented. An airborne Lidar high resolution elevation model was used to analyze the landslide once it occurred. Synthetic stereo pairs were constructed, one previous to the landslide to photo interpret lineaments and one after it to visualize the phenomenon. Plots
\end{abstract}


of transects across pre- and post-landslide elevation models illustrate the magnitude of the landslide. From the Lidar elevation model, a general landslide surface plane was calculated with a slope of $28 \%$ and 239 degrees in azimuth. The different factors that could have triggered the landslide are analyzed, without finding an outstanding one. We consider that the cause was a sum of factors with a delayed response of a few days.

Keywords: Grijalva River, landslides, remote sensing, Lidar, digital elevation model, natural dam formation.

\section{Introducción}

Los deslizamientos ocurren cuando la masa más externa de una ladera, y hasta cierta profundidad, se corta, desliza y se mueve como una unidad pendiente abajo sobre una superficie de falla principal. La masa deslizante se rompe y disgrega conforme se mueve pendiente abajo, generando una masa viscosa que literalmente se vacía talud abajo de la ladera. Su velocidad es variable, desde muy baja hasta muy alta. En la mayoría de los casos, las causas naturales que disparan o activan los deslizamientos son las lluvias intensas y prolongadas, los sismos fuertes y la actividad volcánica, o la combinación de ellas. Para que ello ocurra, deben conjuntarse características geológicas y geomorfológicas propicias (pendiente, altura, agrietamiento, grado de alteración de las rocas, principalmente), así como propiedades mecánicas de los materiales propensas a la falla. Existen también causas inducidas por actividad antropogénica. Desde luego, todos estos deslizamientos son tanto más desastrosos en la medida en que suceden en áreas pobladas y con mayor infraestructura (MendozaLópez et al., 2002).

El bloqueo parcial o total de corrientes de agua a causa de fenómenos naturales no es nuevo. Los deslizamientos de ladera y los flujos de lava o lodo, además de arrasar lo que encuentran en su camino, tienen un segundo efecto al retener o desviar un caudal. Al obstruirse el flujo de la corriente se genera un peligro creciente e inminente para las comunidades e infraestructura establecidas aguas abajo, en las riberas del río y las llanuras de inundación, por la repentina liberación del volumen de agua retenido al colapsarse la barrera natural por el sobreflujo. La acción inmediata para restablecer el flujo es imperativa, a fin de eliminar o disminuir los posibles efectos si no se actúa en consecuencia. Es indispensable contar con información para dimensionar y caracterizar el fenómeno y así establecer un plan de acción que permita atender la contingencia. La teledetección provee de manera rápida y eficiente los insumos necesarios para proponer estrategias de atención. Técnicas emergentes como los levantamientos aéreos del relieve del terreno por medio de rayo láser (Lidar) resultan de suma utilidad en las tareas de diagnóstico y mitigación.

Li (2009) y Zhang et al., (2009) describen el caso del terremoto de magnitud 8 que azotó el 12 de Mayo de 2008 la región de Wenchuan en China. Donde la fuerte sacudida, además de producir un elevado número de muertos $(+$
$69000)$ y heridos (+ 374000$)$, indujo una serie de deslaves que interrumpieron y desviaron el flujo de los ríos en la zona. En sus artículos describen el desastre natural y los insumos de información teledetectada que colectaron como primera respuesta y de los retos que enfrentaron para procesarla rápidamente y guiar los planes de remediación $\mathrm{y}$ rescate.

En este trabajo se presenta una perspectiva de antes y después del deslizamiento a partir de modelos digitales de elevación e imagen satelital, el contexto de la cuenca del río Grijalva, la precipitación anómala y la actividad sísmica que precedió al evento del 4 de noviembre de 2007.

\subsection{La cuenca del río Grijalva}

La cuenca del río Grijalva se localiza en el sureste de México. Es una cuenca transfronteriza de $60256 \mathrm{~km}^{2}$ que se extiende hasta la Sierra de Cuchumatanes en Guatemala, expandiéndose en México a lo largo de la Depresión Central de Chiapas, una extensa zona semiplana con orientación SE-NW flanqueada por la Sierra Madre, Los Altos y las Montañas del Norte de Chiapas (Figura 1). Aguas abajo, el río Grijalva conduce los escurrimientos de las sierras de Chiapas hacia la parte baja de la cuenca, localizada en la Llanura Costera del Golfo, a su vez formada por grandes cantidades de aluvión acarreado por los ríos más caudalosos de México, entre ellos el Grijalva y Usumacinta, los cuales atraviesan esta provincia fisiográfica para desembocar en la parte sur del Golfo de México.

Las condiciones del clima varían radicalmente conforme el Grijalva avanza río abajo. Las cuencas alta (CA) y media (CM) del Grijalva (Figura 1) tienen una precipitación media que oscila entre los 1200 y $1700 \mathrm{~mm}$ anuales, debido a que esta zona se localiza entre dos barreras meteorológicas: las zonas montañosas del norte y la costa de Chiapas, que bajo condiciones del efecto Fohen generan condiciones secas. Sin embargo, a través de Guatemala la influencia de ondas del Este genera la mayor parte de la precipitación en las partes media y alta de la cuenca, donde el $95 \%$ de la precipitación es de origen tropical (RubioGutiérrez y Triana-Ramírez, 2006).

En la parte alta de la cuenca baja se ubica una de las zonas de mayor precipitación en México, con poco más de $4000 \mathrm{~mm}$ anuales. Las lluvias se presentan todo el año por influencia de sistemas tropicales y de invierno. Estos últimos pueden generar cada año precipitaciones de 300 


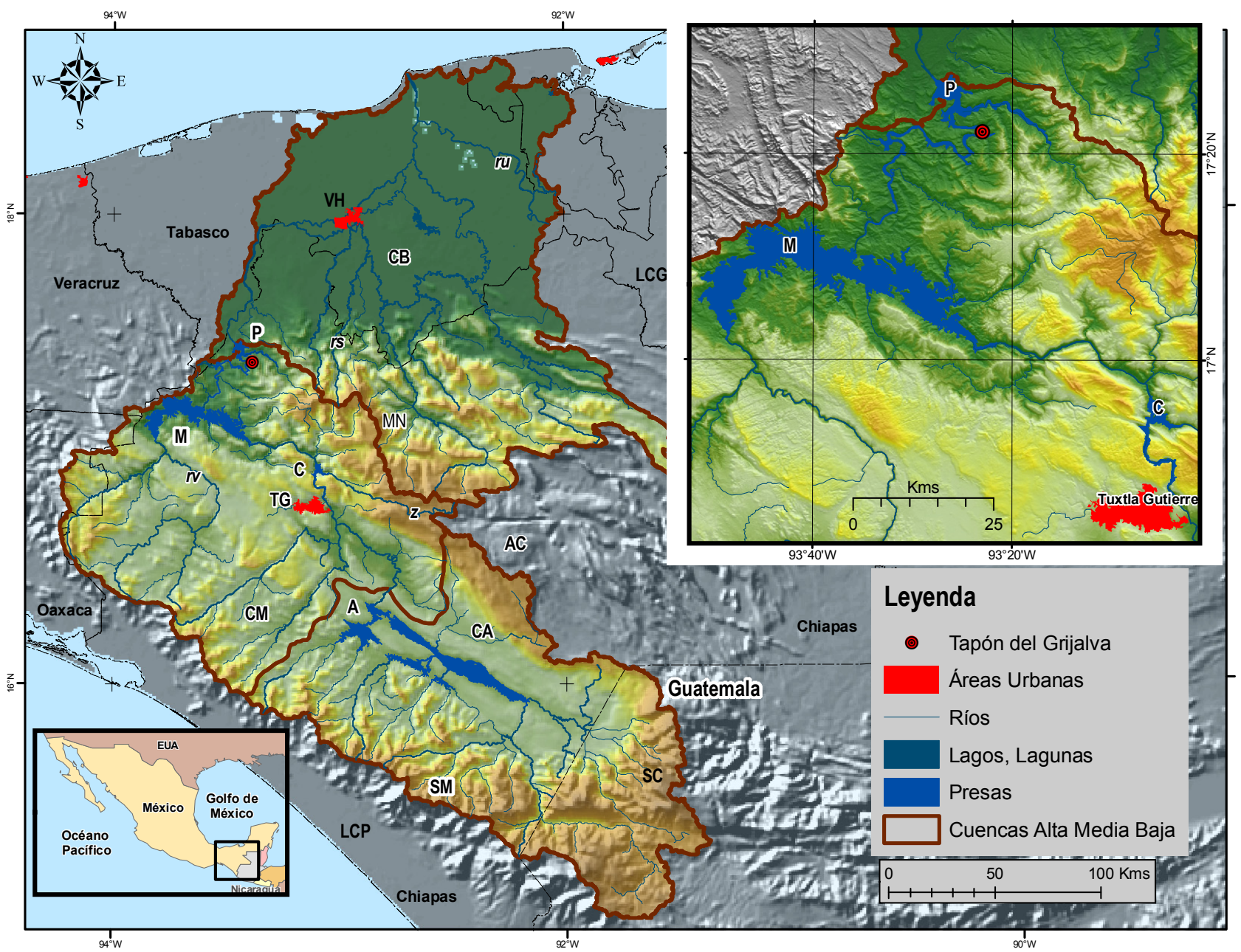

Figura 1. Cuenca y subcuencas del río Grijalva, presa natural emplazada entre presas Peñitas y Malpaso. $(\mathrm{P}=$ Presa Peñitas, $\mathrm{M}=\mathrm{Presa}$ Malpaso, $\mathrm{A}=$ Presa La Angostura, C = Presa Chicoasén, VH = Villa Hermosa, TG = Tuxtla Gutiérrez, SM = Sierra Madre de Chiapas, AC = Los Altos de Chiapas, SC $=$ Sierra Cuchumatanes, $\mathrm{MN}=$ Montañas Norte de Chiapas, $\mathrm{LCP}=$ Llanura Costera del Pacífico, $\mathrm{LCG}=$ Llanura Costera del Golfo, $\mathrm{rs}=$ ríos de la Sierra, $\mathrm{ru}=$ río Usumacinta, rv = río de la Venta, $\mathrm{z}=$ río Zincatán, $\mathrm{CA}, \mathrm{CM}, \mathrm{CB}=$ Cuencas Alta, Media y Baja $)$.

$\mathrm{mm}$ en 24 horas, produciendo grandes escurrimientos debido principalmente a la intensidad de las precipitaciones inducidas por efectos de ascenso orográfico. En la planicie de la cuenca baja $(\mathrm{CB})$ del Grijalva la precipitación anual oscila entre los 1700 y $2300 \mathrm{~mm}$. La influencia de sistemas atmosféricos es similar que en la parte alta de la cuenca baja, pero la precipitación disminuye porque no existen las aportaciones del ascenso orográfico (Rubio-Gutiérrez y Triana-Ramírez, 2006).

El volumen medio anual que escurre hacia la desembocadura del río Grijalva se encuentra alrededor de los 36,500 millones de metros cúbicos $\left(\mathrm{Mm}^{3}\right)$ anuales. Si a este volumen añadimos el volumen medio anual del río Usumacinta, la cantidad de agua dulce que desemboca al Golfo de México por el aporte de estas dos cuencas es de alrededor de 100,000 $\mathrm{Mm}^{3}$ anuales (Rubio-Gutiérrez y Triana-Ramírez, 2006).

El flujo del río Grijalva está parcialmente controlado. En la parte alta de la cuenca, en la Depresión Central de
Chiapas, sus aportaciones son primero retenidas en la presa La Angostura. Aguas abajo, el río bordea la ciudad de Tuxtla Gutiérrez, capital del estado de Chiapas, para continuar hacia la presa Chicoasén, donde confluye el caudal del río Zincatán (Figura 1). Posteriormente el río Grijalva llega a la presa Malpaso, también conocida como Nezahualcóyotl, donde convergen las aportaciones del río La Venta. Después de la cortina de Malpaso, se localiza la presa Peñitas. Entre estas dos presas ocurrió el deslizamiento de ladera que taponeó el flujo natural del río Grijalva, tema estudio de este trabajo. Aguas abajo de la presa Peñitas, el río Grijalva continúa su cauce hacia la Llanura Costera del Golfo, donde se encuentra la ciudad de Villahermosa, capital del estado de Tabasco, donde convergen otras corrientes importantes como los ríos de la Sierra. Las comunidades en estas zonas planas de la llanura, son las más vulnerables a las inundaciones por el desbordamiento de una compleja red de cauces que drenan hacia el Golfo de México las cuencas de los ríos Grijalva y Usumacinta. 
Aplicando herramientas hidrológicas de sistemas de información geográfica (SIG) sobre modelos digitales de elevación SRTM (Farr y Kobrick, 2000), calculamos los límites de la cuenca y subcuencas a partir de puntos de interés a lo largo del cauce del río Grijalva. En particular nos apoyamos en la herramienta de modelado hidrológico de la extensión de análisis espacial de ESRI (2009). Primero calculamos la cuenca a partir de la desembocadura al Golfo de México abarcando su totalidad, para luego avanzar hacia las partes altas de la cuenca considerando las cortinas de las presas como puntos para la delimitación de las subcuencas. Primero en la presa Peñitas, seguido de la presa Malpaso, para continuar en Chicoasén y finalizar en la cortina de la presa Angostura. En la Figura 2 se muestra la subdivisión de la cuenca del Grijalva por presa junto con la ubicación de las estaciones meteorológicas de la Comisión Nacional del Agua (CNA) y la estación del Campo Experimental del Centro de Chiapas (CECECH) del Instituto Nacional de Investigaciones Forestales, Agrícolas y Pecuarias (INIFAP). En la Figura 2 se incluye una relación donde se indica el número de estaciones de la CNA por subcuenca así como el área de la subcuenca y del área acumulada en $\mathrm{km}^{2}$ incorporando las subcuencas aguas arriba. La subdivisión de la cuenca por presa se utilizará en la siguiente sección como unidad espacial de reporte de la precipitación previa al deslizamiento.

Para generalizar y complementar la descripción introductoria de la cuenca del Grijalva, la subdivisión por presas se puede agrupar. Las subcuencas de las presas Peñitas, Malpaso y Chicoasén las podríamos aglutinar en la cuenca media y a partir de la cortina de la presa Angostura sería la cuenca alta. Esta generalización está plasmada en la Figura 1.

1.2. Condiciones hidrometeorológicas de octubre de 2007 en la cuenca del Grijalva

En la segunda mitad de octubre ocurrieron precipitaciones extraordinarias en la cuenca del río Grijalva que generaron grandes escurrimientos a la presa Peñitas y en la

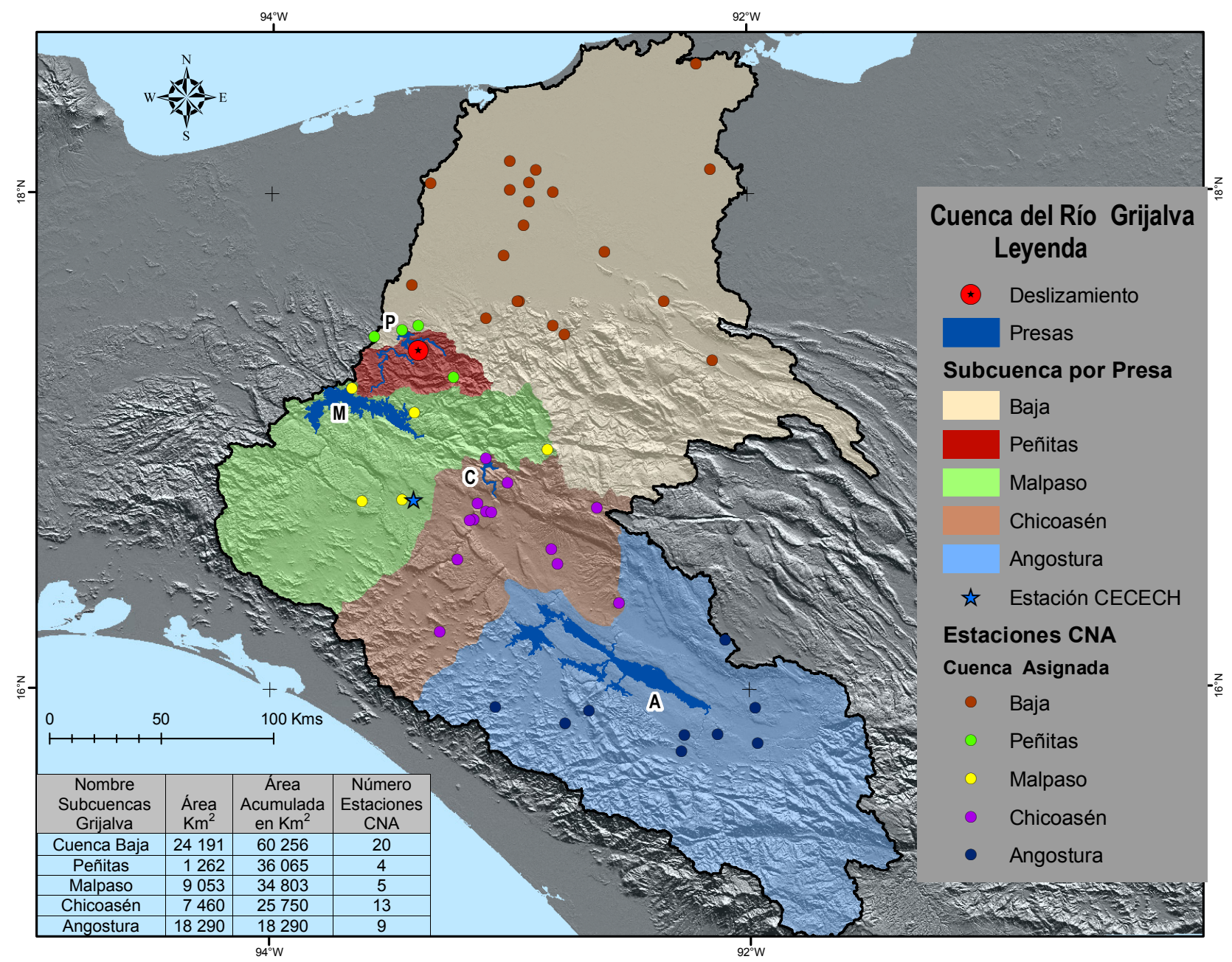

Figura 2. Subdivisión de la cuenca del Grijalva en subcuencas por presa. Ubicación de las estaciones meteorológicas de la Comisión Nacional del Agua (CNA) y del INIFAP simbolizadas por subcuencas. Se incluye una relación de las áreas de las subcuencas y acumuladas incorporando las cuencas aguas arriba, así como el número de estaciones de CNA en cada una. ( $\mathrm{P}=$ Presa Peñitas, $\mathrm{M}=$ Presa Malpaso, $\mathrm{C}=$ Presa Chicoasén, $\mathrm{A}=$ Presa La Angostura). 
planicie del estado de Tabasco. Los escurrimientos los cuales inundaron una superficie cercana al $80 \%$ del territorio de Tabasco, afectando a más de 1 millón de personas. Dos frentes fríos generaron precipitaciones extraordinarias mayores de $400 \mathrm{~mm}$ en $24 \mathrm{~h}$ y cerca de $1000 \mathrm{~mm}$ en tres días (del 28 al 30 de octubre) en la cuenca media del río Grijalva (CAH-SRM, 2008). Previo a estos eventos ocurrieron precipitaciones importantes que mantuvieron saturado el suelo, limitando su capacidad de infiltración. Para este análisis se contó con los resúmenes de precipitación diaria durante los meses de octubre y noviembre de 2007 de las 76 estaciones meteorológicas de la CNA en los estados de Tabasco y Chiapas. De las 76 estaciones, 51 se ubican dentro de las fronteras de las subcuencas del río Grijalva descritas en la sección previa y ubicadas en la Figura 2. En esta figura se alcanza a notar que 2 estaciones (Sayula y Rómulo Calzada) asignadas a la cuenca Peñitas, se ubican dentro del polígono de la cuenca Baja del Grijalva, cerca al límite de la cuenca Peñitas. Sin embargo estas se asignaron a la cuenca Peñitas, debido a su proximidad a esta última y a que los reportes de precipitación por cuenca que se generaron (Tabla 1) coincidieran con el informe de la Comisión de Asuntos Hidráulicos del Senado de la República Mexicana (CAH-SRM, 2008) donde la precipitación de éstas dos estaciones se adjudicó a la cuenca Peñitas.

La precipitación ocurrida en la región fue especialmente intensa durante los días del 28 de octubre al 1 de noviembre de 2007, previos al deslizamiento. Las gráficas de precipitación máxima y promedio diaria por cuenca se presentan en la Figura 3, con los valores correspondientes en la Tabla 1. En ésta última se puede ver que las precipitaciones máximas por día y por cuenca corresponden en su mayoría (4 de 8) a alguna estación de la subcuenca Peñitas, con valores extraordinarios durante varios días y con un
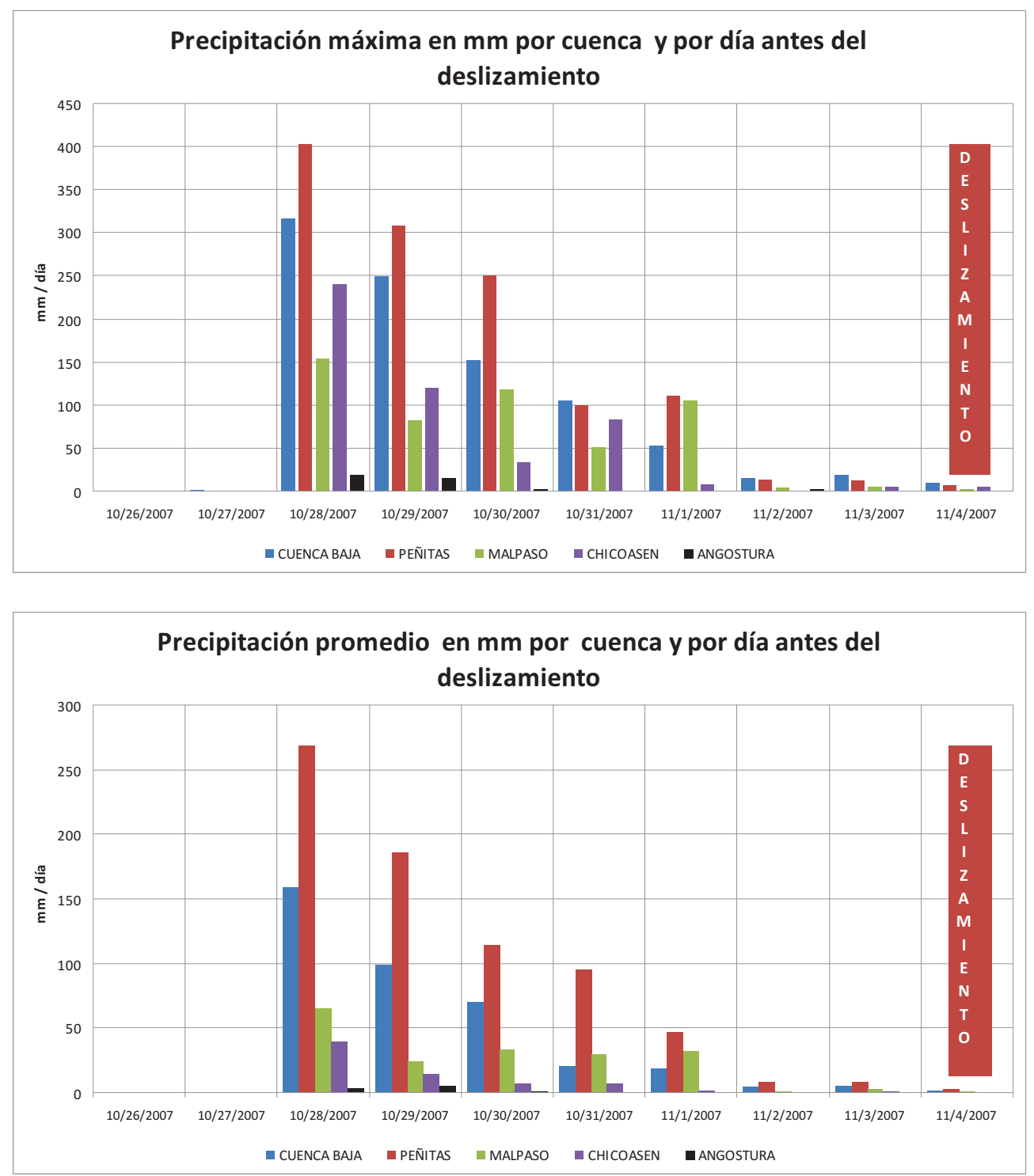

Figura 3. Precipitaciones máximas y promedio, en mm, registradas en las cuencas de la región previas al deslizamiento del Grijalva. Para la precipitación máxima, se reporta el dato registrado en la estación de CNA con mayor precipitación de cada cuenca. 
Tabla 1. Precipitación diaria máxima y promedio en mm, registrada en las cuencas de la región previas al deslizamiento del 4 de noviembre. Para el máximo, se reporta el dato registrado en la estación con mayor precipitación de cada cuenca. Se resaltan los valores más altos por día (fondo gris) para la precipitación máxima así como el promedio.

\begin{tabular}{|c|c|c|c|c|c|c|c|c|c|c|}
\hline \multicolumn{11}{|c|}{ Precipitación máxima en mm por día y por cuenca } \\
\hline \multirow[b]{2}{*}{ Subcuenca } & \multicolumn{6}{|c|}{ Octubre 2007} & \multicolumn{4}{|c|}{ Noviembre 2007} \\
\hline & 26 & 27 & 28 & 29 & 30 & 31 & 1 & 2 & 3 & 4 \\
\hline Cuenca Baja & 0.01 & 1.4 & 317.0 & 249.6 & 152.0 & 105.1 & 53.0 & 14.6 & 19.2 & 9.5 \\
\hline Peñitas & 0.0 & 0.0 & 403.4 & 308.9 & 250.5 & 100.3 & 110.6 & 13.6 & 12.3 & 6.2 \\
\hline Malpaso & 0.0 & 0.0 & 153.0 & 81.8 & 118.7 & 51.4 & 104.5 & 3.6 & 5.5 & 2.2 \\
\hline Chicoasén & 0.01 & 0.0 & 240.0 & 120.4 & 34.0 & 83.0 & 8.4 & 0.3 & 5.0 & 5.0 \\
\hline Angostura & 0.1 & 0.0 & 19.0 & 15.4 & 2.5 & 0.3 & 0.2 & 3.1 & 0.1 & 0.0 \\
\hline \multicolumn{11}{|c|}{ Precipitación promedio en $\mathrm{mm}$ por día y por cuenca } \\
\hline Cuenca Baja & 0.0 & 0.1 & 159.1 & 99.0 & 69.7 & 20.5 & 18.7 & 4.4 & 5.2 & 1.8 \\
\hline Peñitas & 0.0 & 0.0 & 269.0 & 185.9 & 114.1 & 95.1 & 46.8 & 8.2 & 7.7 & 2.5 \\
\hline Malpaso & 0.0 & 0.0 & 65.7 & 24.5 & 33.1 & 29.7 & 32.1 & 1.1 & 2.6 & 0.7 \\
\hline Chicoasén & 0.0 & 0.0 & 39.6 & 14.3 & 6.8 & 7.1 & 1.5 & 0.0 & 0.5 & 0.4 \\
\hline Angostura & 0.0 & 0.0 & 3.8 & 5.4 & 1.1 & 0.1 & 0.0 & 0.3 & 0.0 & 0.0 \\
\hline
\end{tabular}

acumulado de precipitaciones máximas de $1208.5 \mathrm{~mm}$ en la cuenca en los 8 días previos al deslizamiento. En el caso de la precipitación promedio, la totalidad de los valores más altos por día corresponden a la cuenca Peñitas. Para mayor claridad se han resaltado en la Tabla 1 los valores máximos por día.

Además de la información de precipitación diaria de la CNA, se contó con las mediciones cada 15 minutos de una estación meteorológica automática (estación 26017, CECECH-INIFAP) a $65 \mathrm{~km}$ del deslizamiento, aguas arriba en la cuenca de la presa Malpaso. Su ubicación se indica en Figura 2. Para el período del 8 de octubre al 5 de noviembre de 2007, las mediciones de precipitación cada 15 minutos se agruparon por hora y se muestran en la Figura 4 junto con su curva acumulativa. La pendiente de la curva acumulativa es un indicativo de la intensidad de la lluvia en el sitio. En la figura se distinguen tres eventos de precipitación con dos o más días de lluvia continua, el primero del 10 al 12 de octubre con alta intensidad, después uno con menor ímpetu del 23 al 24 y finalmente un evento de precipitación intensa que antecedió al deslizamiento, del 28 al 31 de octubre de 2007.

Como era de esperarse, los escurrimientos durante el mes de octubre también fueron extraordinarios, en particular del día 23 y subsecuentes produjeron una sucesión de crecientes con muy cortos intervalos entre ellas. En el informe de la CAH-SRM (2008) viene un hidrograma con el gasto (Q) en $\mathrm{m}^{3} / \mathrm{s}$ de entrada y salida de la presa Peñitas ( $\mathrm{Q}$ total $=\mathrm{Q}$ turbinas $+\mathrm{Q}$ vertedor de excedencias) así como del nivel de agua en la presa (Figura 5). El sistema de presas del Grijalva contuvo los escurrimientos hasta la presa Malpaso. La presa Peñitas, que tiene poca capacidad, recibió prácticamente sólo los escurrimientos de su propia cuenca de $1262 \mathrm{~km}^{2}$, que, a pesar de no ser muy grande, las precipitaciones en ella si fueron importantes (Tabla 1 y Figura 3). A la presa Peñitas ingresó una cre- ciente los días 11 y 12 de octubre con un caudal superior a los $5000 \mathrm{~m}^{3} / \mathrm{s}$ (Figura 5). Los días del 23 al 26 de octubre se presentó una segunda creciente con un gasto pico de más de $3500 \mathrm{~m}^{3} / \mathrm{s}$, que estaba siendo desalojada de la presa Peñitas cuando se presentó una creciente aún mayor, el 29 de octubre, de alrededor de $5000 \mathrm{~m}^{3} / \mathrm{s}$. Se puede establecer una relación entre los eventos de lluvia intensa registrados en la estación CECECH (Figura 4) y el gasto en la presa Peñitas (Figura 5). A pesar de que la estación se ubica en la cuenca de la presa Malpaso, se puede apreciar en ambas gráficas (Figuras 4 y 5) los eventos del 11, 16, 23 y 29 de octubre. Se informa que la presa Malpaso retenía todo el caudal aguas arriba de la cortina de la presa (CAH-SRM, 2008). Esto nos hace inferir que la precipitación registrada en la estación CECECH tuvo una cobertura regional que abarcó también a la cuenca de la presa Peñitas, como lo confirman la Tabla 1 y la Figura 3 para los días del 28 de octubre al 4 de noviembre de 2007.

Fue necesario desfogar la presa Peñitas a través del vertedor de excedencia en combinación con las turbinas de la planta hidroeléctrica (Figura 5). Esta liberación de excedentes empeoró la ya difícil situación que prevalecía en la ciudad de Villahermosa por las inundaciones, y continuó hasta que fortuitamente se dio el desgajamiento de un cerro aguas arriba que generó un tapón natural del río Grijalva que bloqueó el caudal hacia la presa. Este accidente natural dio una tregua a las comunidades de las llanuras del Golfo al atenuar las inundaciones por el desbordamiento del río (Martines, 2007). Se puede decir que el desgajamiento tuvo un aspecto positivo, sin embargo había que remediar la situación antes de que se diera un sobreflujo con sus consecuencias inesperadas aguas abajo. Después de 44 días de intensos trabajos con equipo pesado, el 18 de diciembre se logró abrir un canal a lo largo del tapón que restableció parcialmente su cauce.

Es importante hacer notar que en el informe $\mathrm{CAH}-$ 


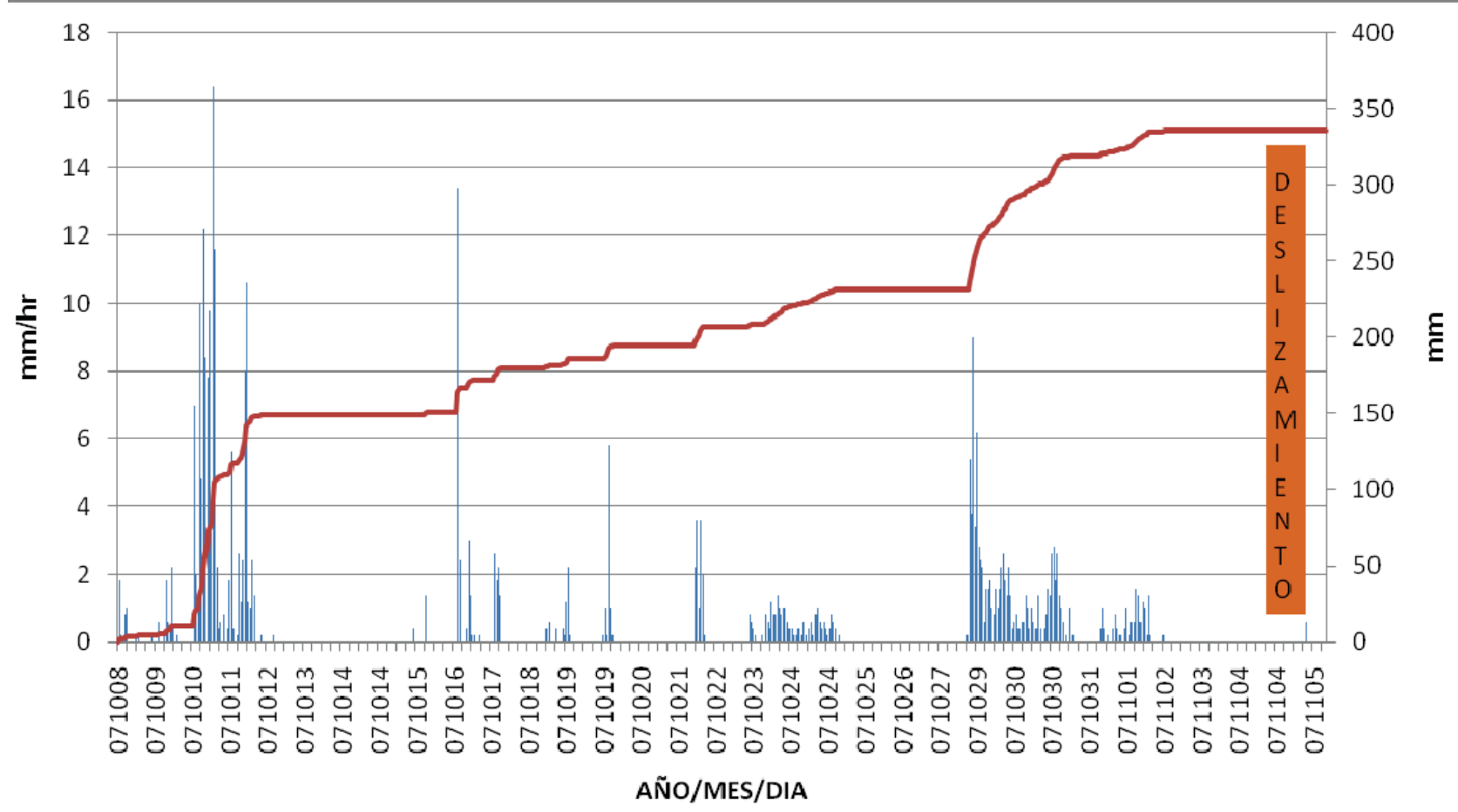

Precipitación - ACUMULADO

Figura 4. Intensidad de la lluvia $(\mathrm{mm} / \mathrm{h})$ en la estación meteorológica del Campo Experimental del Centro de Chiapas (CECECH) del INIFAP, agrupando cada hora las mediciones (15 min) para el periodo de 2007/10/08 al 2007/11/05. Se incluye la gráfica del acumulado en precipitación.

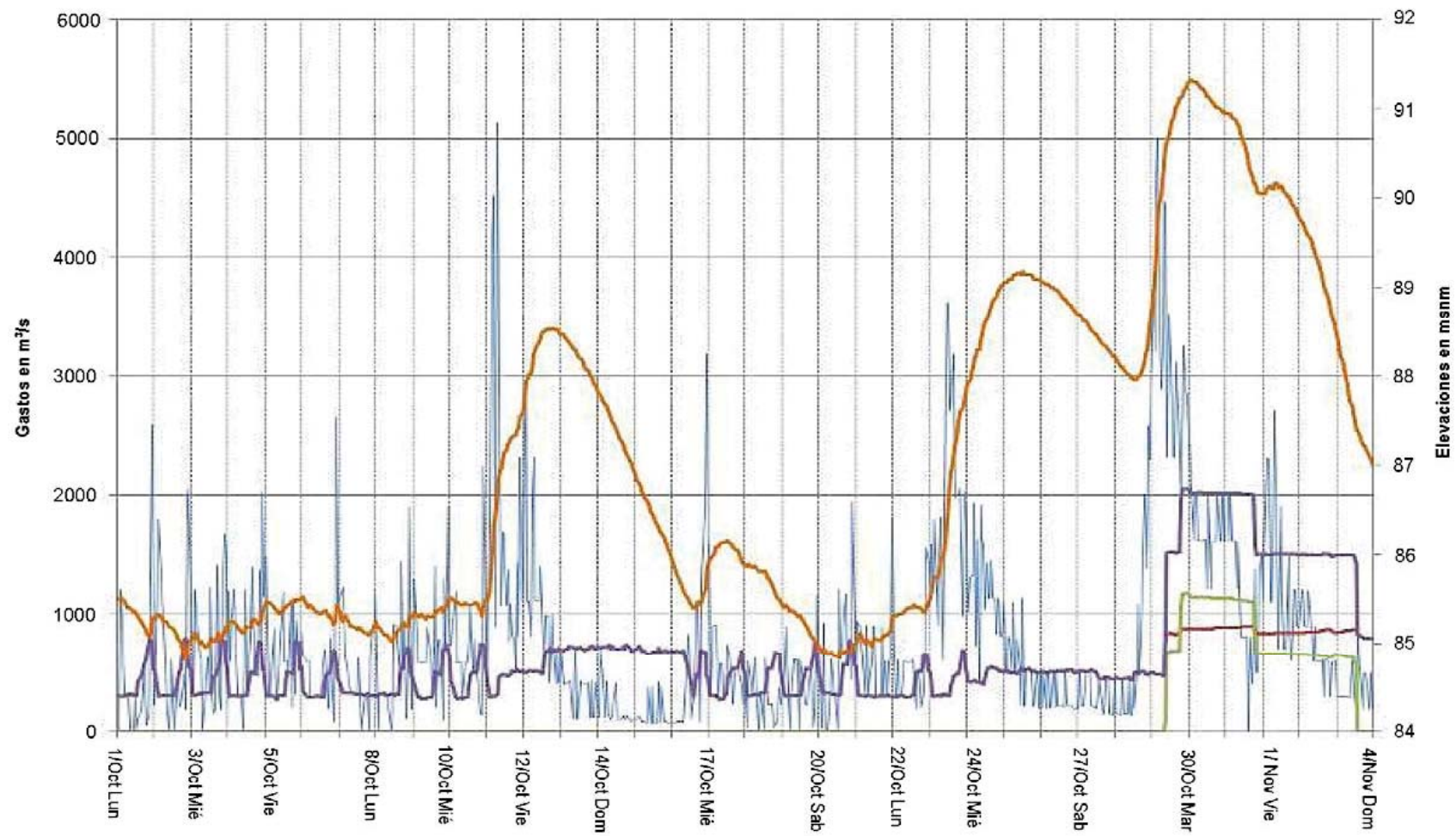

- cuenca propia $\longrightarrow$ turbinas $=Q$ vertedor $\longrightarrow Q$ total Elev. Peñitas

Figura 5. Hidrograma de entrada y evolución de niveles en la presa Peñitas del $1^{\circ}$ de octubre al 4 de noviembre de 2007. Se muestra el gasto (Q) en $\mathrm{m}^{3} / \mathrm{s}$ propio de la cuenca, el canalizado a las turbinas, al vertedor de excedencias y el total. Tomado de CAH-SRM (2008). 
SRM (2008) se presentan las circunstancias que provocaron las inundaciones de la ciudad de Villahermosa y de otras localidades en las llanuras del Golfo, pero no se hace ninguna mención al emplazamiento del tapón del Grijalva por el deslizamiento, situación fortuita que amainó temporalmente el problema de las inundaciones.

\subsection{El deslizamiento de ladera en San Juan de Grijalva}

El 4 de noviembre de 2007, a las 20:32 horas, tiempo local, en el estado de Chiapas (02:32 del 5 de noviembre GMT), ocurrió un gran deslizamiento de ladera en la margen derecha del río Grijalva, a $16 \mathrm{~km}$ aguas arriba de la Presa Peñitas y $57 \mathrm{~km}$ aguas abajo de la presa Malpaso. A lo largo de $600 \mathrm{~m}$ sobre la cresta del cerro La Pera se inició el desprendimiento de un bloque de aproximadamente $1300 \mathrm{~m}$ de longitud y $75 \mathrm{~m}$ de espesor, que se desplomó pendiente abajo, acarreando depósitos de arenisca y lutita de las formaciones La Laja y Encanto del OligocenoMioceno (Islas-Tenorio et al., 2005; Figuras 6 y 7). Las dimensiones anteriores del deslizamiento arroja una área afectada cercana a las 80 ha y un volumen de 55 millones de metros cúbicos. El deslizamiento generó una presa natural en el río Grijalva por medio de un tapón de rocas y suelo con dimensiones aproximadas de $80 \mathrm{~m}$ de altura a lo largo de $800 \mathrm{~m}$ del cauce con un ancho de $300 \mathrm{~m}$.

El derrumbe afectó a la localidad de San Juan de Grijalva en las orillas del río. La masa deslizante, al desplazar las aguas del río, generó una ola de $50 \mathrm{~m}$ de altura que afectó doblemente a la comunidad, primero por el derrumbe y después la ola gigante (Martines, 2007; Alcántara-Ayala y Domínguez-Morales, 2008). Según los datos censales levantados por el Instituto Nacional de Estadística y Geografía (INEGI, 2006), la localidad de San Juan de Grijalva en 2005 contaba con una población de 416 personas y 87 viviendas. En la Figura 6 se muestra una imagen satelital previa al deslizamiento (Digital Globe, 2003), donde se aprecia la ubicación de la comunidad a la orilla del río. Como referencia se sobrepuso un polígono con la huella del deslizamiento. El poblado fue destruido por el deslizamiento y la ola que se generó. Afortunadamente el número

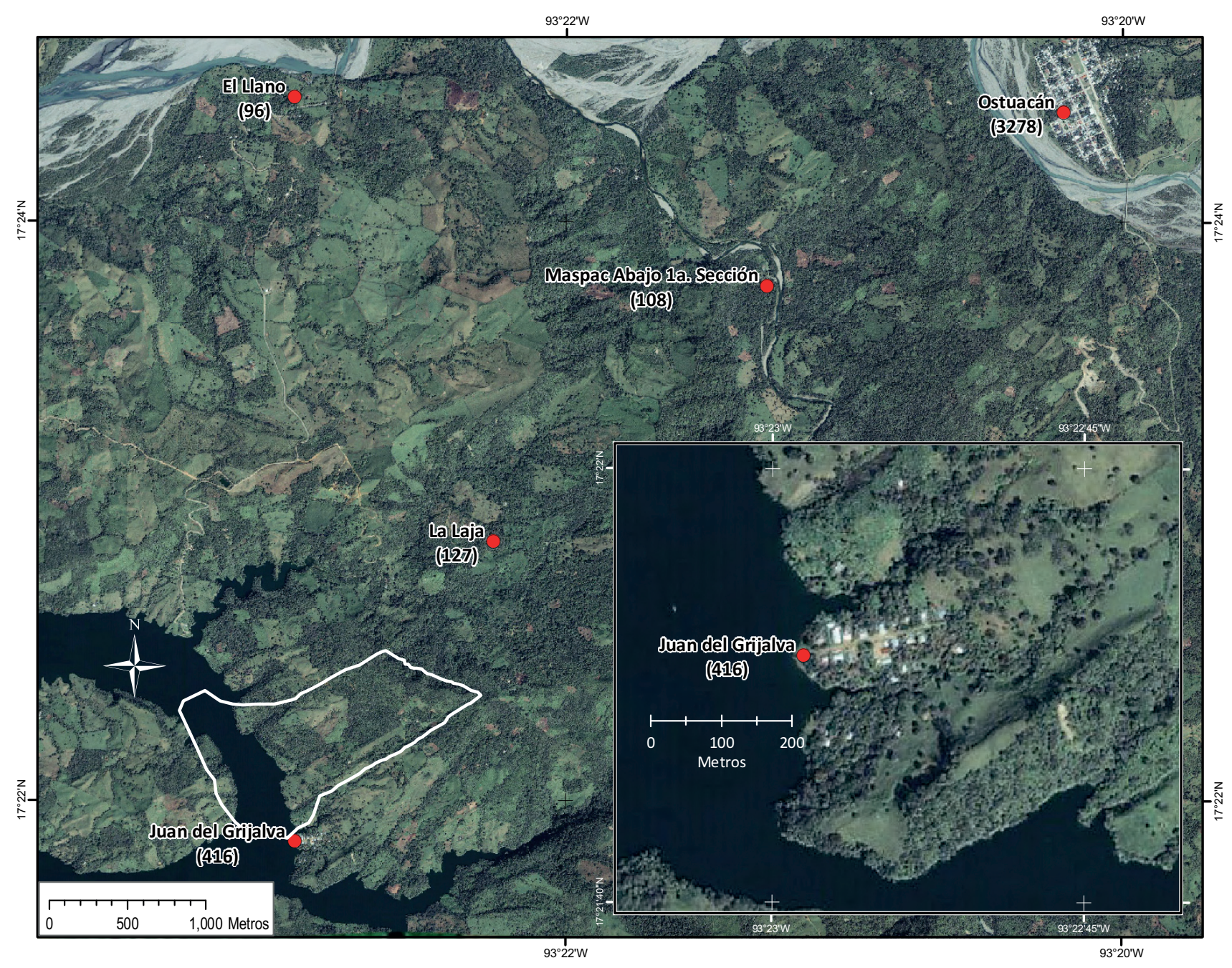

Figura 6. Imagen de la zona de estudio antes del deslizamiento de ladera en San Juan de Grijalva (Digital Globe, 20 de febrero de 2003). Abajo del nombre de cada localidad, se indica la población total tomada del conteo de población y vivienda 2005 (INEGI, 2006). Se sobrepuso la huella del deslizamiento. 


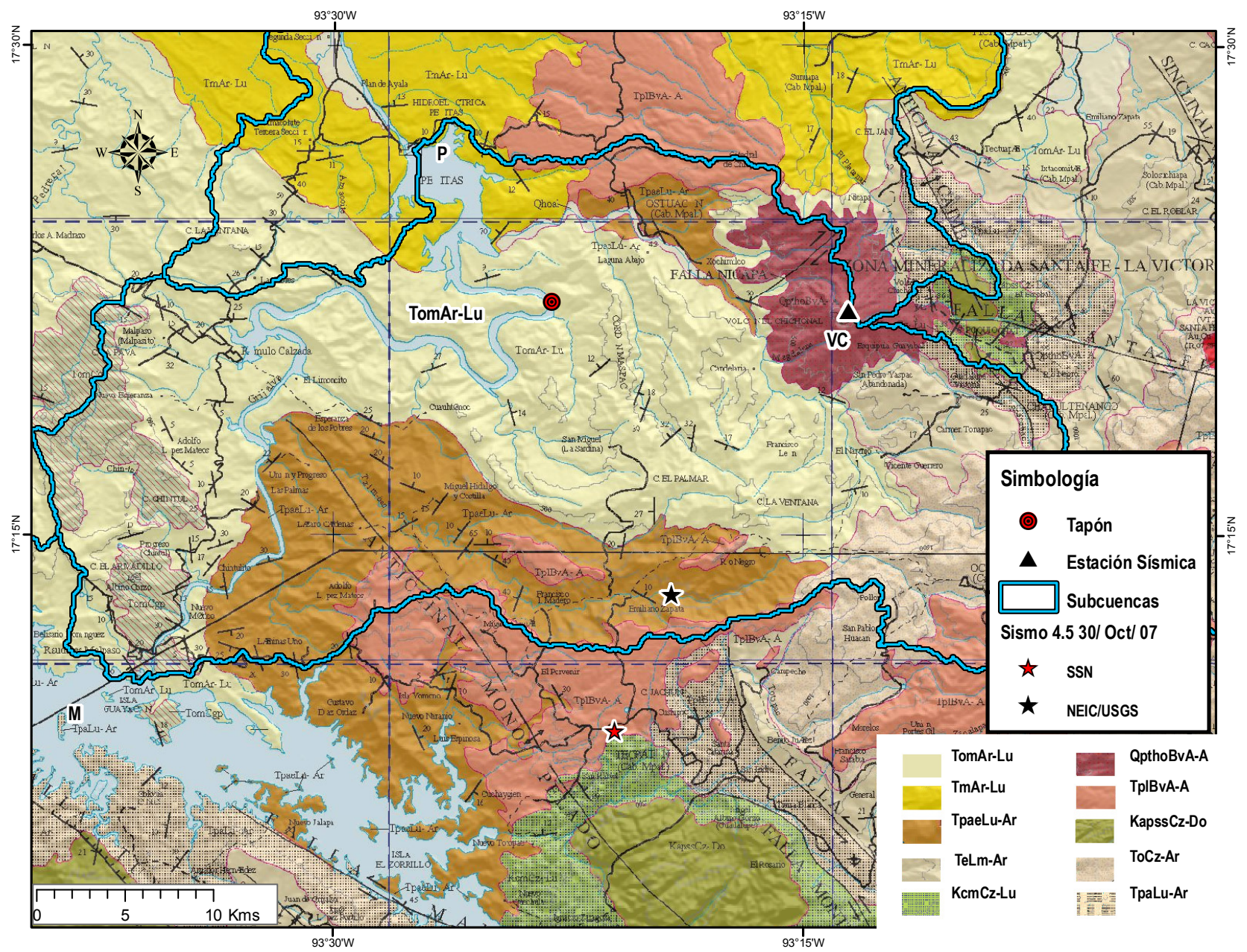

Figura 7. Mapa geológico de la zona (modificado de Islas-Tenorio et al., 2005). El deslizamiento ocurrió en la unidad de arenisca y lutita del Oligoceno-Mioceno de la formación Encanto (TomAr-Lu). Se incluye la localización del sismo magnitud 4.5 del 30 de octubre reportado por el SSN y USGS/ NEIC. Las demás unidades geológicas son: TmAr-Lu, arenisca y lutita de las formaciones Concepción y Filisola del Mioceno Superior; TpaeLu-Ar, lutita y arenisca de la formación Nanchital del Paleoceno-Eoceno; TeLm-Ar, limonita y arenisca depositadas en un ambiente litoral y continental de la formación del Bosque; KcmCz-Lu, caliza y lutita de las formaciones Angostura-Jolpabuchil del Campaniano-Maastrichtiano; QpthoBvA-A, brecha andesítica asociada a evento volcánico del Holoceno; TplBvA-A, brecha andesítica asociada a un evento volcánico del Pleistoceno; KapssCz-Do, caliza-dolomia de la formación Sierra Madre del Aptiano-Santoniano; ToCz-Ar, caliza y arenisca de la formación Mompuyil del Oligoceno; TpaLu-Ar, lutita y arenisca de la formación Soyaló de facies de cuenca. Se incluyen los límites de la cuenca Peñitas calculada entre las cortinas de las presas Malpaso (M) y Peñitas (P). Otras abreviaturas: VC = Volcán Chichonal, $\mathrm{SSN}=$ Servicio Sismológico Nacional, NEIC = Nacional Earthquake Information Center.

reportado de muertes (25) fue reducido comparado con la población total (Alcántara-Ayala y Domínguez-Morales, 2008). Ostuacán, la cabecera municipal se localiza a $7 \mathrm{~km}$ al NE del deslizamiento.

Considerando la clasificación de deslizamientos de tierra por el Servicio Geológico de los Estados Unidos, USGS (2004) por sus siglas en inglés, este evento corresponde al tipo translacional o deslizamiento de bloques, el cual se presenta sobre suelos homogéneos en un lomerío con pendiente pronunciada. Este tipo de deslizamiento se mueve sobre una superficie de ruptura plana. Su velocidad de ocurrencia va desde extremadamente lento hasta extremadamente rápido. Alcántara-Ayala y Domínguez-Morales, (2008) reportan que el estruendo del deslizamiento fue tan intenso que las vibraciones producidas por éste fueron registradas durante aproximadamente 80 segundos en una estación sismológica a los pies del volcán Chichonal, a 16 $\mathrm{km}$ al Este del sitio (Figura 7). En la siguiente sección se hace un breve análisis de la sismicidad previa reportada en los catálogos.

\subsection{Sismicidad previa al deslizamiento}

La mayoría de los deslizamientos relacionados a sismos, ocurren durante o inmediatamente después de la ocurrencia del sismo (Harp y Jibson, 1996; Dadson et al., 2004). Buscando otros factores que pudieran haber influenciado el deslizamiento, se exploró la actividad sísmica registrada en los catálogos del Servicio Sismológico Nacional de México $\left(\mathrm{SSN}^{1}\right)$ y del Centro Nacional de

1 http://www.ssn.unam.mx/ 
Información Sísmica del USGS (NEIC²). En ellos no se reporta actividad sísmica importante en los alrededores del deslizamiento inmediatamente antes de éste. Se reporta un sismo de magnitud 4.5 para el 30 de octubre (09:45:03 GMT) en las inmediaciones del deslizamiento previo al derrumbe, esto es de 5 días antes y coincide en el tiempo con el último evento de precipitación. La localización del epicentro del SSN lo ubica a $24 \mathrm{~km}$ del deslizamiento y la de NEIC a 18 km (Figura 7). Más próximos en el tiempo ocurrieron dos eventos sísmicos de magnitud similar (4.3 y 4.4) en una ventana de 28 horas previas al deslizamiento. Sin embargo los epicentros de estos sismos se localizan a más de $310 \mathrm{~km}$ del derrumbe, uno $11 \mathrm{~h}$ antes en el estado de Oaxaca y otro $28 \mathrm{~h}$ antes, en la trinchera oceánica del Pacífico próxima al estado de Chiapas. Por su lejanía y magnitud, consideramos que éstos 2 eventos no tuvieron ningún efecto en el derrumbe.

El Centro Nacional de Prevención de Desastres (CENAPRED ${ }^{3}$ ) mantiene la estación sismológica del volcán Chichonal. En ella se registraron las vibraciones producidas por la caída de los bloques. La agencia reporta una duración aproximada de 40 segundos de la traza sísmica (Guevara-Ortiz, 2010).

\section{Métodos y materiales}

Apoyándonos en herramientas de teledetección y SIG, se analizaron imágenes satelitales de alta resolución espacial, en combinación con modelos digitales de elevación para examinar el sitio antes y después del deslizamiento. Se fotointerpretaron las estructuras previas al deslizamiento y se examinó el relieve del terreno para caracterizar la superficie del deslizamiento. El resumen de insumos teledetectados se muestra en la Tabla 2.

\subsection{Misión de vuelo Lidar aerotransportado de INEGI}

El lidar aerotransportado es un sensor activo que consta de un telémetro emisor de luz láser y de un espejo que desvía el haz perpendicularmente a la trayectoria del avión. Este desplazamiento lateral, combinado con la trayectoria del avión, permite realizar un barrido del terreno en donde el sensor genera y emite una serie de pulsos láser, los cuales, al pegar con los objetos o el terreno, reflejan o devuelven al sensor parte de la energía del pulso emitido. Con esto, la medida de la distancia entre el sensor y el objeto iluminado por el láser es determinada a través del intervalo de tiempo entre la emisión y la reflexión o retorno del pulso. Para cada pulso emitido puede registrarse hasta tres retornos y para cada uno de ellos también la intensidad reflejada (INEGI, 2008).

Para ubicar de manera precisa las coordenadas de cada punto que reflejó el rayo láser se emplean conjuntamente

2 http://earthquake.usgs.gov/regional/neic/

3 http://www.cenapred.unam.mx/es/ la unidad de medición inercial (IMU, por sus siglas en inglés) y el sistema de posicionamiento global (GPS, por sus siglas en inglés). La unidad de medición inercial, permite medir la orientación del sensor. Este sistema mide la variación de los ángulos de inclinación originados por los movimientos y giros del avión durante el vuelo a fin de determinar la posición del sensor. El sistema de posicionamiento global del avión, en combinación con el apoyo terrestre de las estaciones base, registra la posición espacial del avión cada medio segundo. Cuando el rayo láser llega al terreno o los objetos sobre de él, se presentan diferentes formas de retorno. En una superficie sólida (edificios, suelo, vehículos, entre otros), el rayo se refleja de manera inmediata al sensor. En el agua y el vidrio, el rayo de luz presenta reflexión especular (dispersión), que hace que el reflejo no retorne al sensor y para estas áreas no se registran datos. En algunas zonas volcánicas, en lugares con presencia de carbón y cuando existe asfalto reciente, el rayo es absorbido y no es posible obtener datos. En zonas de vegetación, el rayo choca con la capa superior de los árboles y una parte del rayo retorna al sensor (primer retorno), pero otras partes pueden penetrar entre los huecos del follaje hasta chocar con algún objeto y retornar (segundo retorno), y otras partes siguen penetrando hasta que son reflejadas por el suelo cuando la vegetación no es muy densa (tercer retorno) (INEGI, 2008).

Los modelos digitales de elevación del tipo superficie son derivados del sistema de láser aerotransportado. Consiste en una matriz de datos de elevación interpolados a partir de los puntos clasificados del primer retorno y que corresponden tanto al terreno como a objetos presentes en el suelo, como infraestructura y vegetación. Por otro lado, los modelos digitales de elevación de tipo terreno son interpolados también a partir de la nube de puntos, pero utilizan con mayor peso los últimos retornos, que son los que penetran más, viajan mayor distancia y representan al terreno más que a la cubierta vegetal, cuya superficie se reconstruye con los primeros retornos. A los modelos digitales de elevación de tipo terreno se les conoce también como modelos de suelo desnudo (bare Earth en inglés) ya que tienen el efecto de remover la cubierta vegetal.

Los modelos digitales de elevación se utilizan para determinar la configuración y la altura del terreno. A partir de ellos se pueden modelar las alturas y obtener otros aspectos, tales como pendientes, secciones, desniveles, áreas sujetas a inundación, generación de curvas de nivel, volúmenes de tierra, delimitación de cuencas, etc., que pueden ser útiles en aplicaciones de cartografía, animación en 3D para simuladores de vuelo, estudios hidráulicos e hidrológicos, ingeniería civil, gestión de zonas de costa, estudios de la vegetación, mantenimiento y gestión de líneas eléctricas, etc. (INEGI, 2008).

El 20 de diciembre de 2007, 46 días después del deslizamiento, el INEGI inicio un vuelo para obtener datos lidar de la zona de San Juan de Grijalva. Con las nubes de puntos, el INEGI generó los modelos digitales del terreno 
Tabla 2. Resumen de insumos teledetectados para analizar la zona antes y después del deslizamiento ocurrido el 2007/11/04. Para los insumos posteriores se indica cuantos días después.

\begin{tabular}{lcccc}
\hline \multicolumn{1}{c}{ Tipo } & Fecha & Tiempo & Resolución espacial (m) & Fuente \\
\hline $\begin{array}{l}\text { Modelo Digital del Terreno } \\
\text { Imagen Satelital }\end{array}$ & 2003 & antes & 30.0 & INEGI (2003) \\
$\begin{array}{l}\text { Color Natural } \\
\begin{array}{l}\text { Modelo Digital del Terreno } \\
\text { Lidar }\end{array}\end{array}$ & $2003 / 02 / 20$ & antes & 0.60 & Digital Globe (2003) \\
$\begin{array}{l}\text { Imagen Satelital } \\
\text { Color Natural }\end{array}$ & $2007 / 12 / 20$ & 46 días después & 1.0 & INEGI (2007) \\
\hline
\end{tabular}

y superficie con $1 \mathrm{~m}$ de resolución espacial. En este trabajo se utilizó el modelo digital de elevación tipo terreno para analizar el deslizamiento. Este se muestra sombreado, texturizado con una rampa de color y con isolíneas de altura en la Figura 8. Para su mejor interpretación, se incluye la huella de la extensión del deslizamiento. Se puede apreciar la diferencia de altura entre la cima, cerca de la corona del deslizamiento con $320 \mathrm{~m}$, y la base, con menos de $100 \mathrm{~m}$. Se puede distinguir también un promontorio a 200-220 m de altura, en la parte media del deslizamiento, donde se detuvo un bloque poco perturbado que se trasladó desde la cima hasta este punto. El canal de desfogue de la presa natural, excavado con maquinaria pesada, quedó plasmado en el modelo lidar atravesando el tapón en su parte central. Dada la emergencia, éste fue un esfuerzo coordinado por el gobierno de México en colaboración con firmas de ingeniería para desfogar la presa natural. De otra manera, ésta sería finalmente rebosada, con consecuencias impredecibles aguas abajo, en particular afectando la presa hidroeléctrica Peñitas. Es importante resaltar la diferencia de altura en el nivel del agua en ambos lados del tapón. Por un lado se registran una altura cercana a los $100 \mathrm{~m}$ y aguas abajo la lámina de agua está por debajo de los $80 \mathrm{~m}$. En los resultados se presenta un perfil de elevación con los datos lidar a lo largo del canal, indicando la altura del nivel del agua. El canal que desfogó el tapón se abrió el 18 de diciembre, dos días antes que se iniciara la colección de datos lidar y 44 días después del deslizamiento. Dos días después de que se inició el vaciado de la presa natural, los datos lidar registraron un desnivel de $19 \mathrm{~m}$. Inferimos que la diferencia en altura en el nivel del espejo de agua fue mayor antes de que se abriera el canal. En su momento se informó que el nivel del agua subía a una tasa de $2 \mathrm{~cm} / \mathrm{h}$ (Del Solar R., 2007); esto se traduce en $21 \mathrm{~m}$ de desnivel para los 44 días de acumulación de agua.

\subsection{Pares estereoscópicos sintéticos}

La visión estereoscópica en 3 dimensiones de la superficie terrestre hace evidentes rasgos que en visión monoscópica pueden pasar desapercibidos. Es práctica común en el análisis geomorfológico la fotointerpretación del relieve con apoyo de un estereoscopio y fotos aéreas del mismo sitio tomadas desde dos posiciones distintas. Esto se logra con el traslape de fotos aéreas sucesivas en líneas de vuelo o con el traslape entre líneas de vuelo contiguas. El efecto 3D se logra sobre las zonas de traslape entre fotos, analizando la foto izquierda y derecha (el par) con ayuda del estereoscopio. No es requisito contar con fotos tomadas del mismo sitio desde dos posiciones distintas, es posible crear sintéticamente la imagen izquierda y derecha para su interpretación estereoscópica. Las imágenes estereoscópicas artificiales proveen perspectivas en la interpretación de patrones geológicos y geomorfológicos a escala local y regional, en comparación con el análisis monoscópico. Entre las ventajas que presentan los modelos estereoscópicos sintéticos se pueden mencionar que:

- Sólo se necesita una imagen aérea o de satélite con su respectivo modelo de elevación.

- La exageración vertical puede ser ajustada al tipo de terreno o a la preferencia del intérprete.

- El intérprete experimenta un mínimo en el forzamiento de la vista porque la sobreposición entre las imágenes es del $100 \%$ y además el par izquierdo tiene los mismos colores y contrastes que el par derecho.

- Se pueden generar vistas sinópticas de grandes extensiones geográficas que proporcionan una perspectiva global, imposible de reproducir con fotografía aérea.

Los modelos estereoscópicos artificiales son creados a través del procesado de imágenes individuales, generando la vista izquierda y derecha. Las vistas son generadas al introducir un pequeño corrimiento a cada elemento de la imagen (píxel) como función de la elevación en cada punto y puede ser formulado con la siguiente ecuación:

$$
\Delta p=\Delta h(k)
$$

donde $\Delta p$ es el desplazamiento en el paralaje horizontal en cada una de las celdas, el cual es proporcional a la diferencia en altura de la celda $(\Delta h)$ con respecto a un valor de referencia. La constante $k$ determina el desplazamiento del paralaje en la visión estereoscópica y controla la exageración vertical de los objetos.

Este principio se conoce desde mediados de la década de los setenta (Batson et al., 1976; Kowalik, 1993; Sabins, 1987), pero no es utilizado con frecuencia porque requiere de herramientas informáticas especializadas. Los pares estereoscópicos sintéticos son de gran utilidad en la foto interpretación de la geomorfología. 


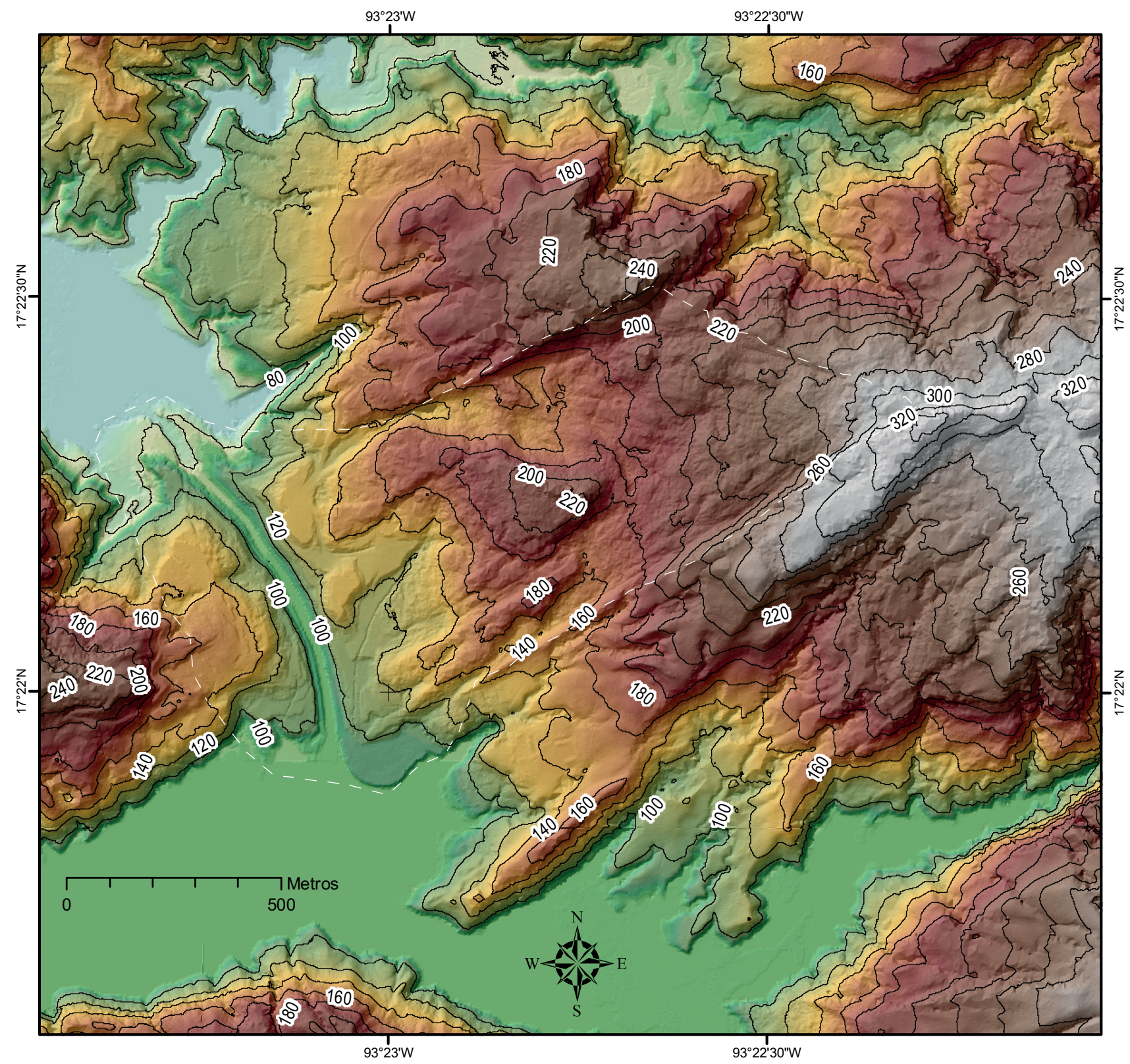

Figura 8. Modelo digital lidar tipo terreno de la zona del deslizamiento, sombreado y texturizado con escala de color para la altura. Se sobrepone la huella del deslizamiento (línea blanca).

\subsection{Cálculo del plano de falla}

Además de las herramientas estándar de todo SIG para el cálculo de la pendiente y la orientación del terreno, recurrimos al método de mínimos cuadrados para inferir la profundidad del plano de falla por debajo de la zona de acumulación a partir de la zona expuesta de la falla en la parte alta del deslizamiento. Dadas las características de este deslizamiento, la superficie del desliz se puede modelar con un plano a través de su ecuación general en tres dimensiones:

$$
a \boldsymbol{x}+b \boldsymbol{y}+c \boldsymbol{z}+d=0
$$

donde las constantes o coeficientes $a, b, c$ y $d$ determinan la orientación y pendiente del plano. Si obtenemos por algún medio los valores de los 4 coeficientes, podemos evaluar cualquier punto que se ubique sobre el plano. Si de la ecuación 2 despejamos $z$ y dividimos todo entre su coeficiente $c$, podemos reescribir la ecuación general del plano como

$$
\boldsymbol{z}=e \boldsymbol{x}+f \boldsymbol{y}+g
$$

donde $e=-a / c, f=-b / c$ y $g=-d / c$. Así obtenemos otra forma de la ecuación general del plano en 3 dimensiones, donde ahora tenemos que encontrar 3 coeficientes $(e, f, g)$ en lugar de 4. Además, de esta manera es directa la construcción 
de un sistema de ecuaciones a partir de coordenadas conocidas $(\boldsymbol{x}, \boldsymbol{y}, \boldsymbol{z})$ del plano. En este caso serán coordenadas de la superficie de la falla en la zona expuesta, evaluadas a través del modelo de elevación del terreno lidar posterior al deslizamiento. Entonces, si evaluamos las coordenadas en $m$ posiciones distintas representativas del plano de falla, construimos un sistema sobredeterminado de $m$ ecuaciones con 3 incógnitas $(e, f, g)$ que podemos resolver por mínimos cuadrados. Se requerirá un mínimo de 3 posiciones para resolver el sistema. Con los coeficientes $e, f$ y $g$ obtenidos en la solución, podemos calcular la profundidad de la superficie de deslizamiento por debajo de la zona de acumulación y así estimar el volumen desplazado, que sería aquel entre la superficie del plano de deslizamiento y el modelo de elevación previo al derrumbe.

$$
\left[\begin{array}{l}
z_{1} \\
z_{2} \\
\vdots \\
z_{m}
\end{array}\right]=\left[\begin{array}{lll}
x_{1} & y_{1} & 1 \\
x_{2} & y_{2} & 1 \\
\cdots & & \\
x_{m} & y_{m} & 1
\end{array}\right]\left[\begin{array}{l}
e \\
f \\
g
\end{array}\right]
$$

\section{Resultados}

\subsection{Pares estereoscópicos sintéticos y su interpretación}

Con el método descrito en la sección 2.2, se construyeron pares estereoscópicos sintéticos para explorar en visión estereoscópica la geomorfología antes y después del deslizamiento. Para el caso previo se utilizó el modelo digital de INEGI de $30 \mathrm{~m}$ de resolución complementado con una imagen satelital de alta resolución $(0.60 \mathrm{~m})$ en color natural tomada el 20 de febrero de 2003 (Digital Globe, 2003). Con apoyo del estereoscopio, se fotointerpretaron una serie de lineamientos, plasmados en la Figura 9 junto con la huella del deslizamiento, y la cresta del cerro de la Pera. Se distinguen varios rasgos lineales desde la orilla del río hasta la cima del cerro, incluso unos que se extienden allende la cima, como el lineamiento L2. Los flancos del deslizamiento, indicados en color rojo en la Figura 9, son paralelos y cercanos a los lineamientos L2 y L5, revelando la preexistencia de fallas y fracturas geológicas que favorecieron el colapso. El histograma direccional de los lineamientos muestra una dirección media de 236 grados de azimut.

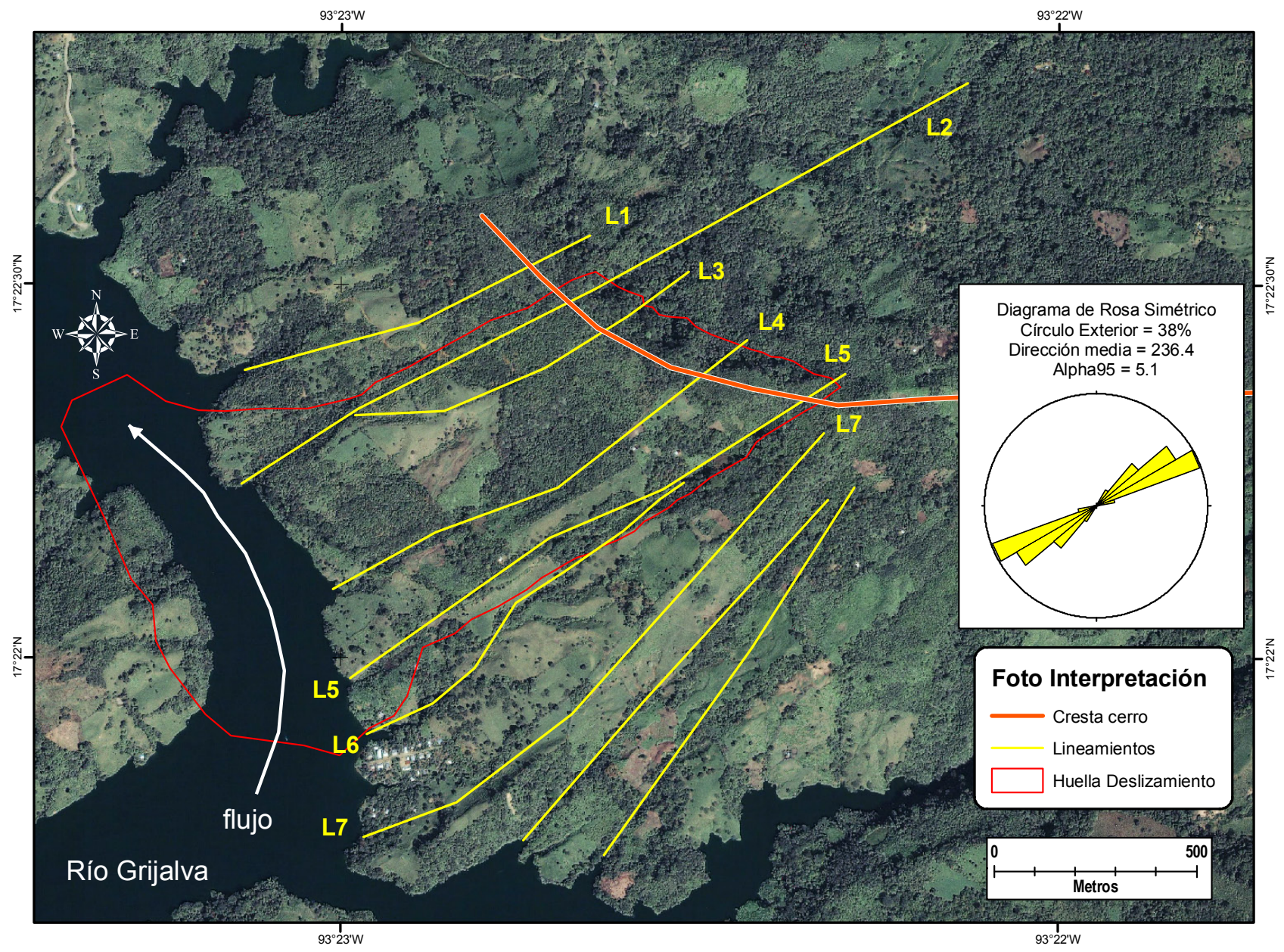

Figura 9. Lineamientos fotointerpretados del estereopar previo al deslizamiento. Se incluye su histograma direccional y se enumeran los lineamientos para su posterior alusión. Como referencia, se delinea la cresta del cerro de la Pera y la huella del deslizamiento. 
En la Figura 10 se presenta el par estereoscópico sintético construido a partir del modelo digital del terreno lidar del 20 de diciembre de 2007 (INEGI, 2008) y de una imagen satelital tomada el 18 de febrero de 2008 (Digital Globe, 2008). El efecto de tercera dimensión se puede apreciar utilizando un estereoscopio, solo necesita imprimir el par izquierdo y derecho de la Figura 10 a la misma escala, ya sea a color o en escala de gris. La escala vertical fue exagerada para resaltar el deslizamiento. Con la visión estereoscópica se puede percibir la profundidad y magnitud del deslizamiento. También se puede ver cómo un bloque se deslizó desde la cima hasta la parte media sin alterar la orientaron y posición relativa de los árboles, y se reubicó pendiente abajo en la ladera, como si fuera un pastel que se deslizó con las velitas puestas. También se alcanza apreciar la zona de acumulación en la base, las crestas y grietas transversas al deslizamiento. No se incluye en el trabajo el estereopar sintético previo al deslizamiento. Para el lector interesado se le puede facilitar una copia contactando al autor de correspondencia.

\subsection{Balance de masa}

En un deslizamiento hay que considerar la conservación de la masa como una premisa. Lo que se remueve en algún lado se deposita en otro. La masa removida en las partes altas de la ladera es desplazada por gravedad hacia las partes bajas; el balance debe ser cero. Los modelos digitales de elevación nos ayudan a identificar las zonas donde hubo remoción de masa y donde ésta se acumuló, comparando el modelo de elevación de antes con respecto al de después del deslizamiento. Esto se puede lograr, ya sea realizando operaciones matriciales entre ellos como una diferencia o cociente, o a través de transectos o perfiles predefinidos que evalúan la altura a lo largo de ellos. En este caso hay que considerar que los modelos digitales del terreno de antes y después tienen importantes diferencias en la resolución espacial (30 m vs $1 \mathrm{~m}$ ), así como la exactitud de éstos. En el levantamiento lidar se usó tecnología más moderna y precisa que la empleada para obtener el modelo de elevación de antes; sin embargo, es la única fuente de información disponible con una perspectiva anterior para hacer la comparación. A pesar de estas disparidades, y por la magnitud del deslizamiento, las operaciones entre los modelos de elevación y los perfiles a través de ellos nos indican claramente las zonas donde hubo pérdida y ganancia neta de masa.

Se hizo una serie de perfiles a través de los modelos de elevación en la zona del deslizamiento. Su ubicación se muestra sobre las imágenes satelitales de antes y después (Figura 11). Los perfiles de los transectos se presentan en las Figuras $12 \mathrm{a}$ y $12 \mathrm{~b}$. Siete transectos cruzan el deslizamiento normalmente con dirección NW-SE y están etiquetados de la A a la G desde la parte alta del cerro a la base, cerca del cauce del Grijalva. Perpendiculares a estos, se trazaron otros 3 perfiles, que van desde la base, en el cauce obstruido del río Grijalva, hasta la cima del cerro de la Pera. Estos perfiles están etiquetados de norte a sur como 0,1 y 2 . Finalmente, se hizo otro transecto a lo largo del canal de desfogue $(\mathrm{H})$, desde la parte más baja hacia aguas arriba. La dirección de los transectos se indica con la punta de flecha, siendo ésta la parte final del perfil. Apoyándonos en herramientas de SIG, se interpolaron las alturas a lo largo de los transectos en ambos modelos de elevación para obtener perfiles de altura. Los perfiles de después (lidar) se indican las Figuras $12 \mathrm{a}$ y $12 \mathrm{~b}$ en color azul marino y los de antes en color azul claro.

En el análisis de los perfiles se hace referencia a los lineamientos fotointerpretados en el estereopar anterior al deslizamiento, plasmados y enumerados en la Figura 9. De los perfiles que cortan normalmente al deslizamiento, el perfil A, que se ubica en la corona de éste, se observa que ambos (antes y después) siguen las variaciones del terreno en la ladera norte del cerro y cortan el lineamiento L2 a los $180 \mathrm{~m}$ del transecto. De los 400 a los $700 \mathrm{~m}$ se aprecia una divergencia entre los perfiles, sin embargo el deslizamiento no es muy evidente. Para la zona de fractura (perfiles B, C y D) se identifican importantes diferencias de altura entre los dos modelos, del orden de 70 a $80 \mathrm{~m}$. En los tres perfiles de después que cortan el modelo lidar (color azul marino), se distinguen claramente, entre los 100 y $700 \mathrm{~m}$ de los perfiles, los escarpes de la falla en los flancos del deslizamiento con una pronunciada pendiente. La distancia entre los escarpes es del orden de $600 \mathrm{~m}$. El escarpe del flanco norte es más profundo que el del sur, lo que sugiere una superficie de ruptura inclinada que más adelante se confirma con el análisis de la superficie expuesta del deslizamiento. En estos tres perfiles (B, C y D) también se distingue el lineamiento L5 (anotado en la Figura 12a) aproximadamente a los $600 \mathrm{~m}$ del perfil que corta el modelo de elevación previo (azul claro) y que coincide con el flanco sur del deslizamiento. En el perfil $\mathrm{B}$, tanto en el modelo de antes como el de después, vuelve a aparecer, a los $150 \mathrm{~m}$, el lineamiento L2, que coincide con el flanco norte del deslizamiento. En general, en estos tres transectos los perfiles del modelo lidar (después) están por debajo de los de antes, lo que indica pérdida de masa.

La zona de acumulación del derrumbe corresponde a los perfiles E, F y G; el perfil lidar del transecto E cruza el bloque que se deslizó de la cima y se distingue claramente en la parte central de éste por una estructura convexa con abruptas pendientes en ambos lados, con una diferencia de altura cercana a los $50 \mathrm{~m}$. En la parte media, el perfil lidar sobrepasa al modelo de antes, indicando acumulación. En el perfil del modelo lidar del transecto $\mathrm{F}$ se presenta una situación invertida al perfil $\mathrm{E}$, que consiste en una estructura cóncava en la parte media de éste con dos estructuras convexas a los lados; el perfil G (Figura 12b), el de mayor longitud de los transversales al deslizamiento, tiene un segmento (de los 600 a los $900 \mathrm{~m}$ ) donde la elevación del perfil lidar es mayor que el otro, en la zona de acumulación. La mayor parte del material se depositó sobre el 


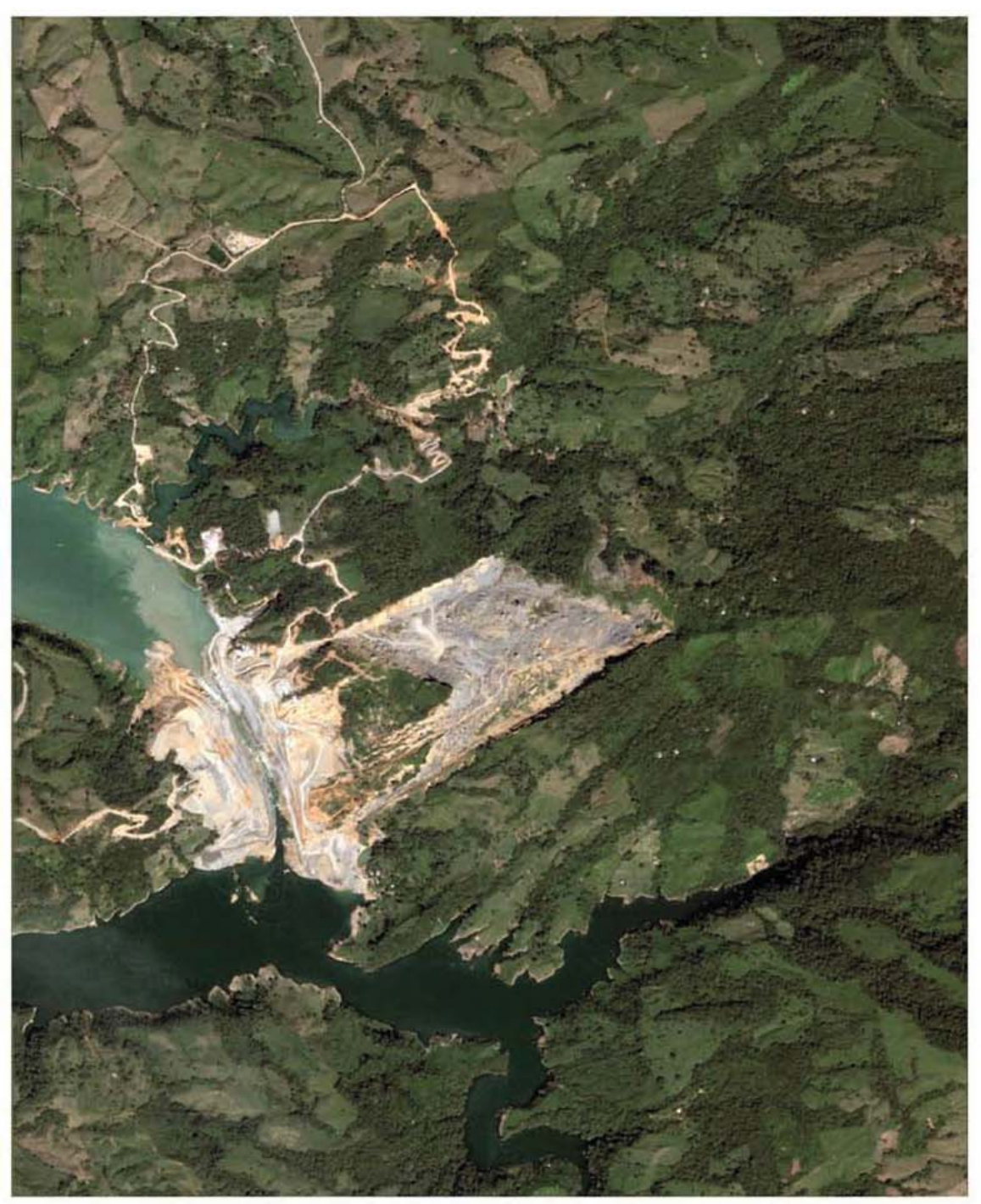

Izquierdo

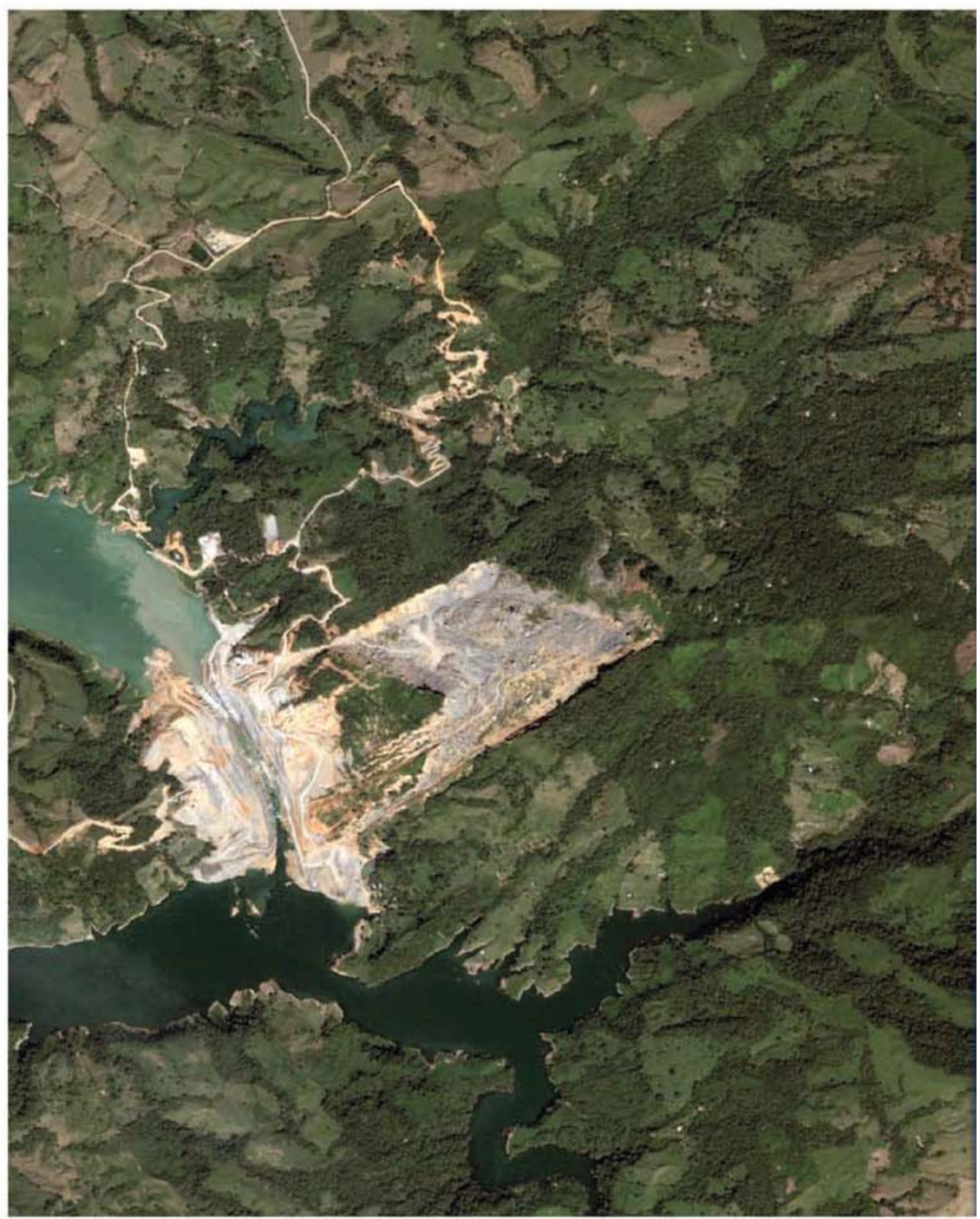

Derecho

Figura 10. Par estereoscópico sintético del deslizamiento generado con el modelo digital del terreno lidar (2007/12/20) y con imagen satelital (2008/02/18) de librería de imágenes de Digital Globe. Para su mejor interpretación, se ha exagerado la escala vertical. 

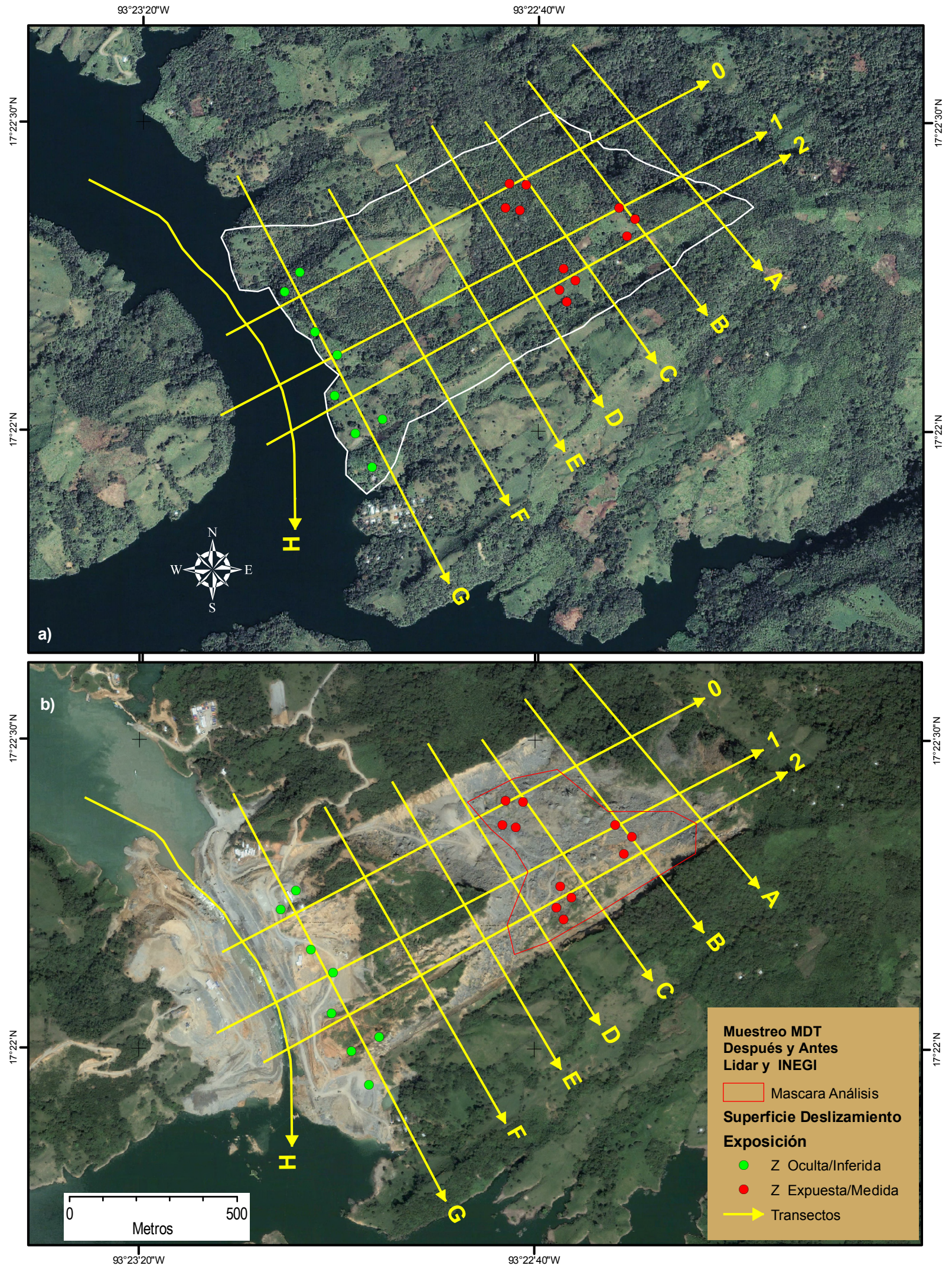

Figura 11. Ubicación de los transectos, del polígono de análisis de la pendiente del terreno en rojo, y puntos de muestreo de posición (x, y, z), también en rojo, para el cálculo del plano de la superficie de deslizamiento. En verde, los puntos donde se infiere la profundidad ocluida del plano de falla. Estas líneas (transectos), polígonos y puntos (de muestreo) se utilizan para extraer información de los modelos de elevación. Las imágenes satelitales de antes a) y después b) están de fondo con el único propósito de ubicación dentro del contexto del deslizamiento. 
TRANSECTO "A"

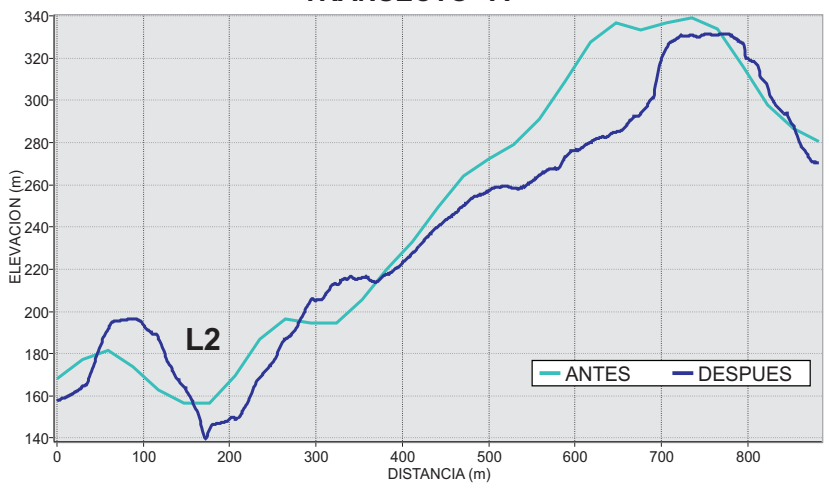

TRANSECTO "C"

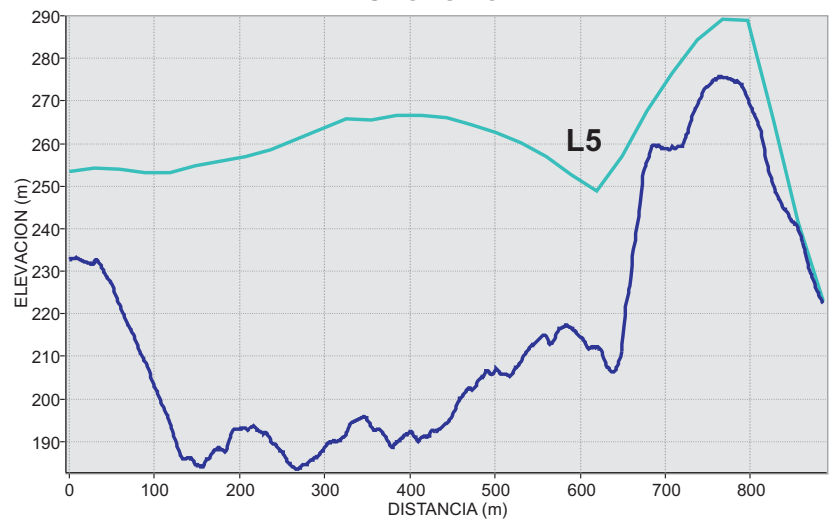

TRANSECTO "E"

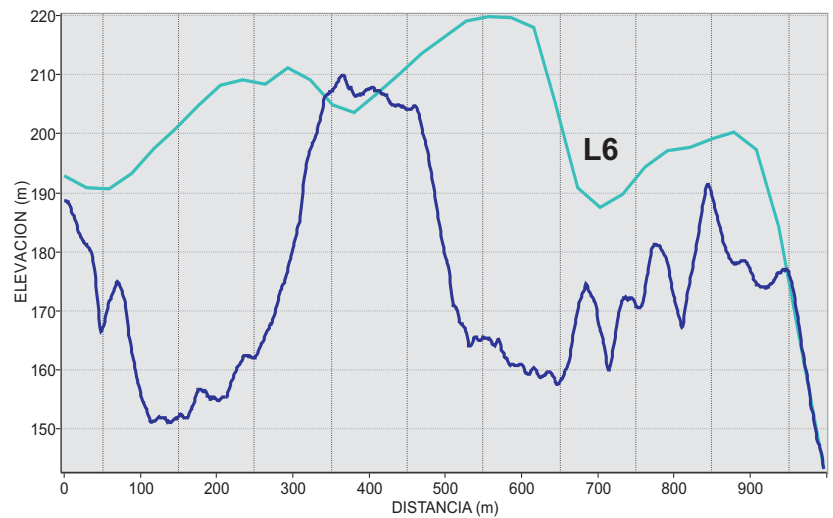

TRANSECTO "B"

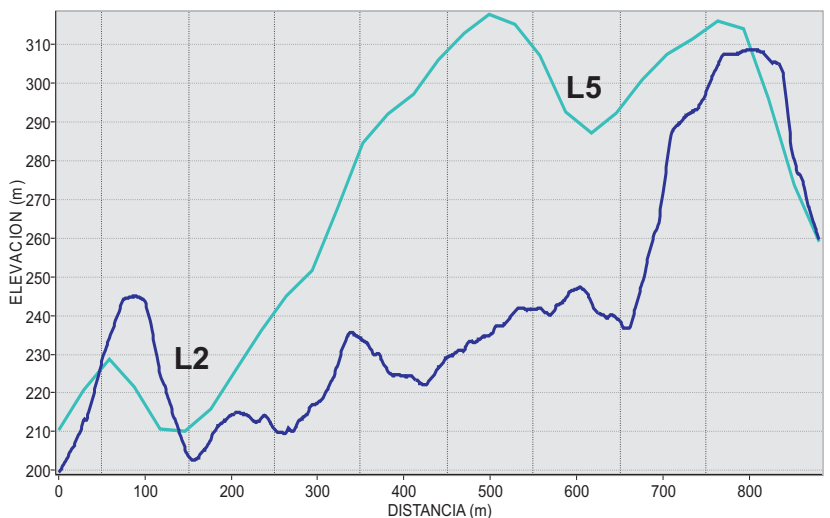

TRANSECTO "D"

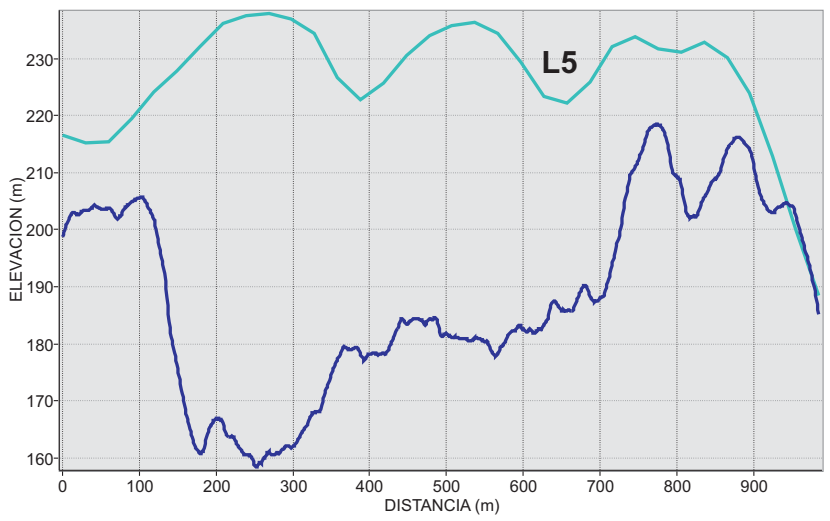

TRANSECTO "F"

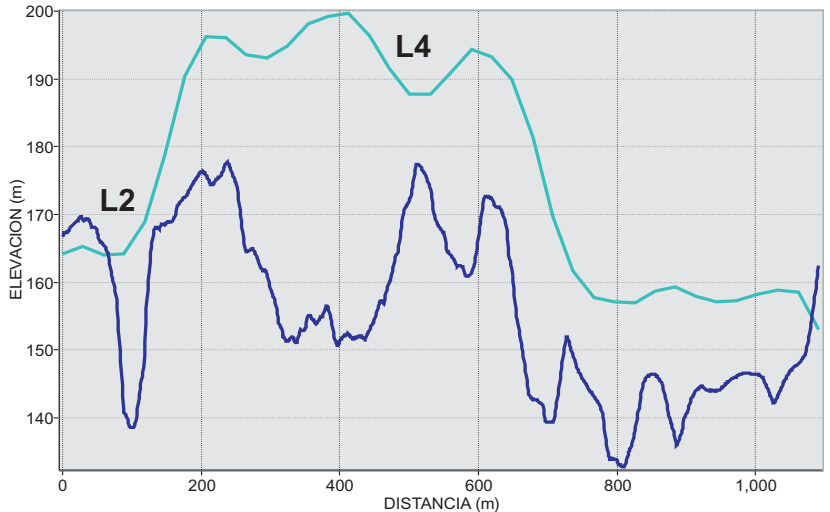

Figura 12a. Transectos A al F con orientación NW-SE, perpendicular al deslizamiento, a través de los modelos digitales del terreno de antes (INEGI, 30 $\mathrm{m}$, en azul claro) y después (lidar, $1 \mathrm{~m}$, en azul marino) del deslizamiento. Para ubicar los transectos consultar Figura 11. Sobre algunos de los perfiles previos (azul claro) se sobreponen anotaciones de la ubicación de los lineamientos fotointerpretados del estereopar previo al deslizamiento (Figura 9).

cauce del río Grijalva, creando un promontorio que hubo que remover para restablecer el flujo. En los transectos de la zona de acumulación (E, F y G) también se anota la posición de los lineamientos de la Figura 9. El perfil G, el más largo y próximo al río Grijalva, es el que cruza más lineamientos (L1, L4, L6 y L7).

En el modelo de elevación lidar aparecen las obras de canalización. Este también registró la diferencia en altura en ambos lados del tapón natural y captó el desnivel dos días después de que se iniciara el desfogue a través del ca- nal. En el transecto H, a lo largo del canal, sólo se muestra el perfil del modelo de elevación lidar, y se alcanza apreciar una diferencia de nivel de $19 \mathrm{~m}$ en los espejos de agua del río Grijalva, desde los $69 \mathrm{~m}$ en la parte baja hasta los $88 \mathrm{~m}$ en la parte alta.

Son interesantes los transectos que van de la base a la cima (Figura 12b), perpendiculares al resto. Ellos nos muestran las principales secciones del derrumbe y la naturaleza plana de la superficie de deslizamiento en su parte expuesta. En la parte alta se distingue la remoción 
TRANSECTO "G"

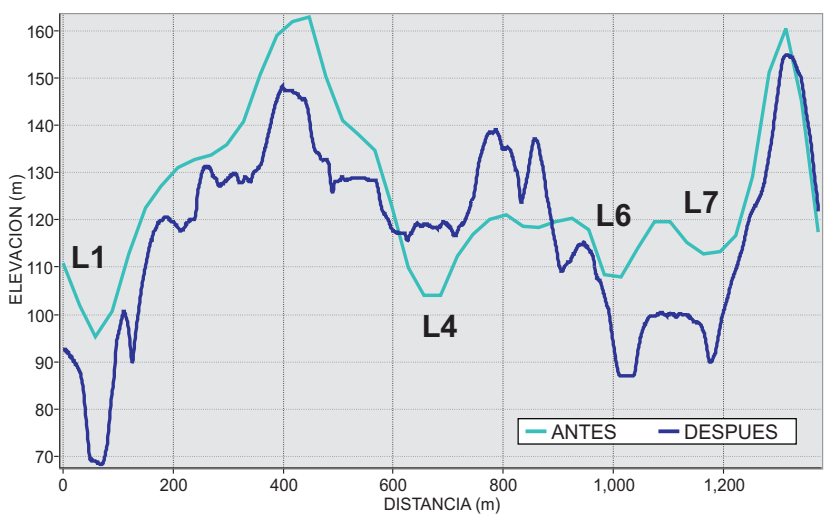

TRANSECTO "0"

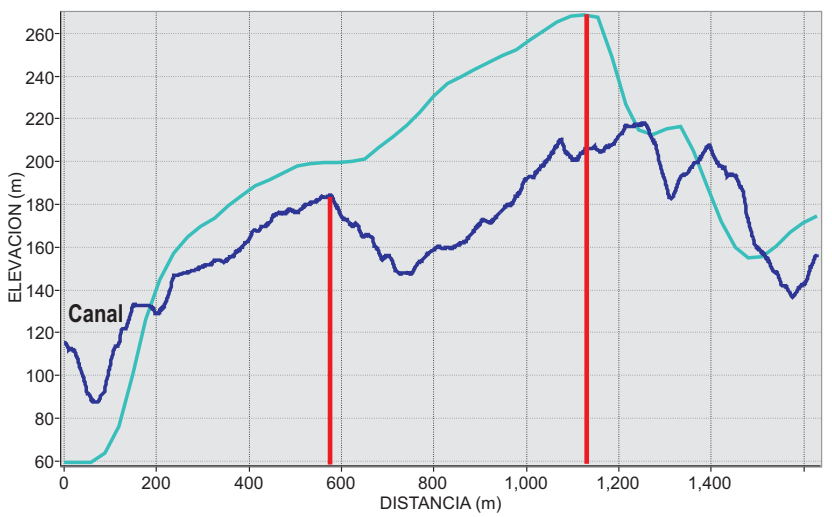

TRANSECTO "H"

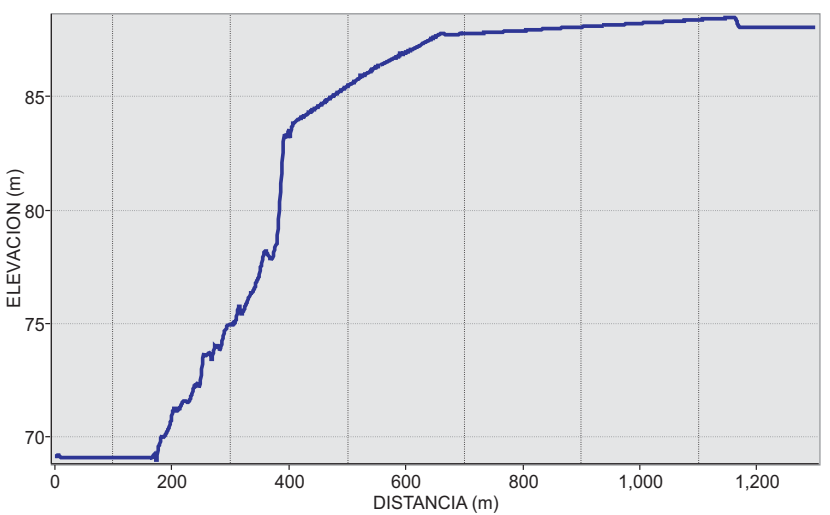

TRANSECTO "1"

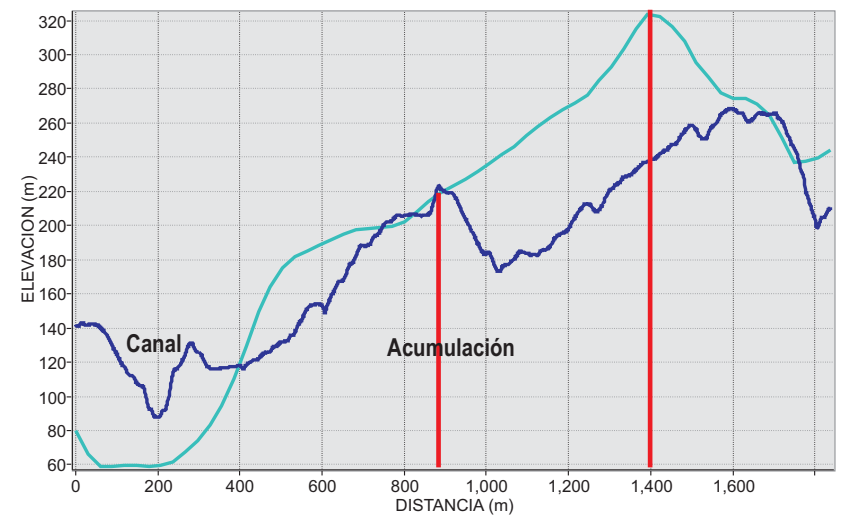

TRANSECTO "2"

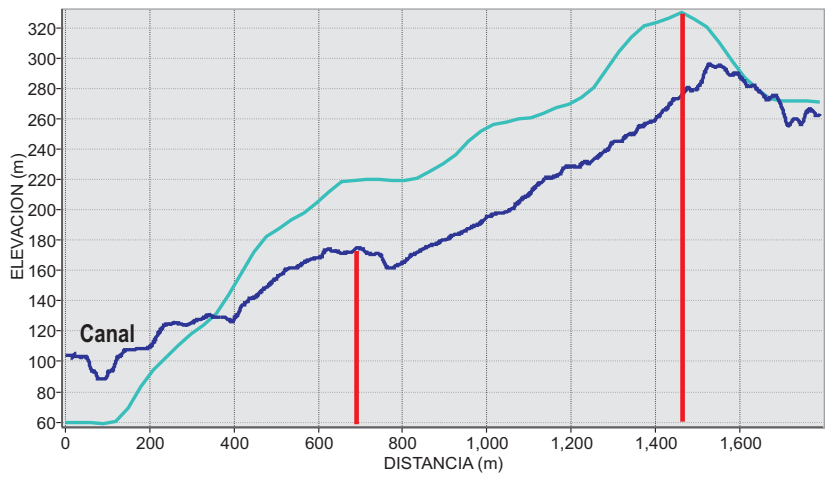

Figura 12b. Transectos G con orientación NW-SE, H a lo largo del canal de desfogue, y 0,1 y 2 de la base a la cima del cerro a través de los modelos digitales del terreno de antes (INEGI, $30 \mathrm{~m}$, en azul claro) y después (lidar, $1 \mathrm{~m}$, en azul marino) del deslizamiento. Para ubicar los transectos consultar Figura 11. Sobre algunos de los perfiles previos (azul claro) se sobreponen anotaciones de la ubicación de los lineamientos fotointerpretados del estereopar previo al deslizamiento (Figura 9).

de masa con respecto al perfil previo, como inició el desprendimiento desde la ladera norte del cerro de la Pera, a partir de 40 a $50 \mathrm{~m}$ de la cima del cerro. En la sección media se alcanza apreciar nuevamente el bloque que se deslizó desde la cima a lo largo de una distancia cercana a los $500 \mathrm{~m}$ en los perfiles 0 y 1 , y de $700 \mathrm{~m}$ en el perfil 2. Para facilitar la interpretación de la distancia recorrida por la cima de cerro, se introdujeron ejes verticales en color rojo. En la parte baja se advierte la zona de acumulación donde ya se delinea el canal de desfogue producto de las obras con maquinaria pesada. Hay que tomar en cuenta que el modelo de elevación de antes no incorpora la batimetría del río Grijalva, hueco donde se depositó la mayor parte del material desplazado que produjo el tapón. En las partes bajas de estos transectos, en los primeros $400 \mathrm{~m}$, es donde los perfiles de los datos lidar están por encima de los del modelo de elevación de antes, lo cual indica la acumulación.

Una forma de estimar los movimientos de masa es por medio de una diferencia entre los modelos de elevación, es decir una operación entre matrices, celda por celda entre ambos modelos, donde el orden de los términos nos indi- 


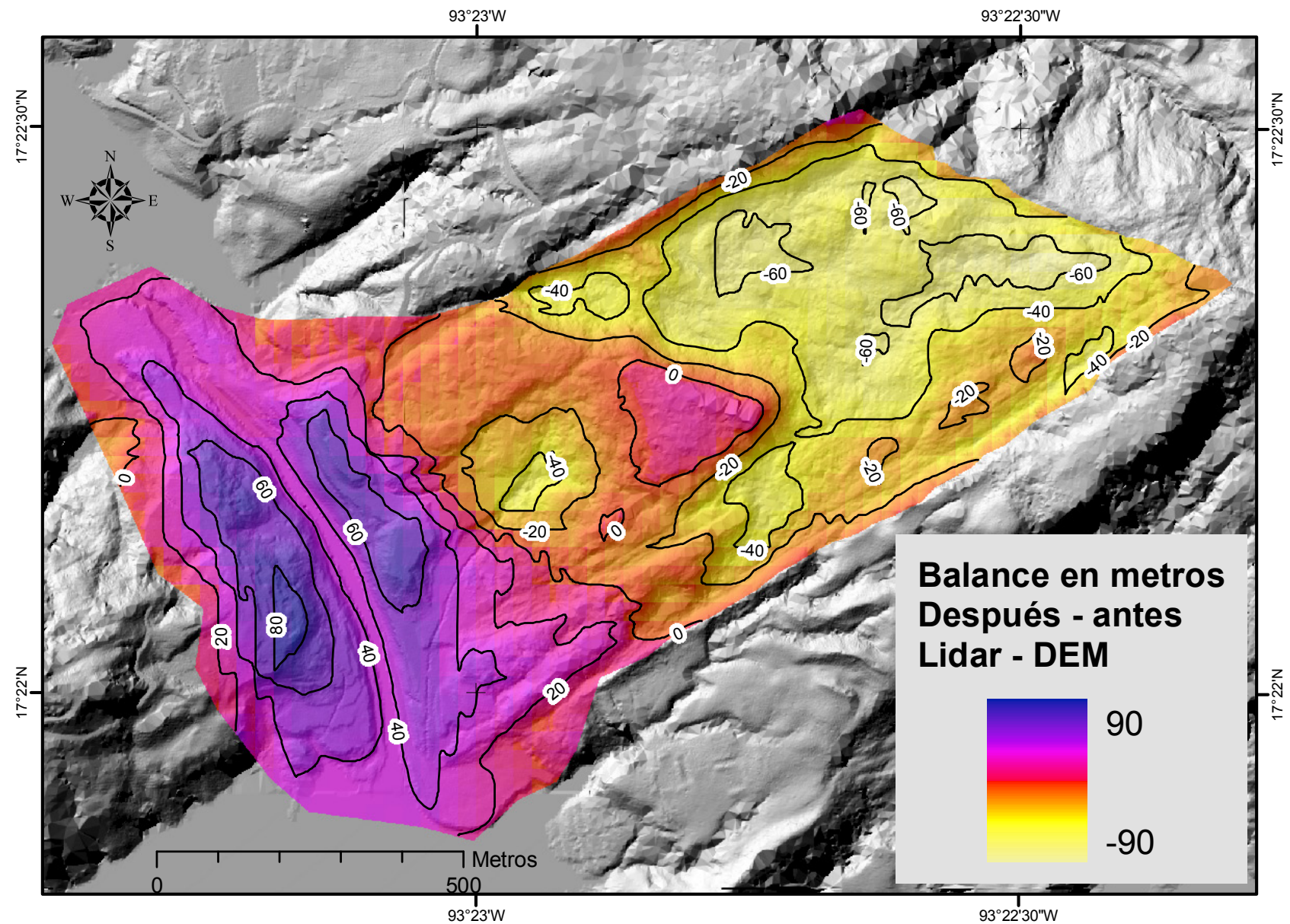

Figura 13. Diferencia entre el modelo digital del terreno de después (lidar $1 \mathrm{~m}$ ) y antes (modelo digital del terreno $30 \mathrm{~m}$ ) del deslizamiento donde se aprecian las zonas de pérdida (negativas) y acumulación (positiva) neta de masa.

cará el signo de la perdida y ganancia de masa. En este caso, calculamos la diferencia de lidar - modelo digital de elevación (DEM), es decir después - antes, donde valores negativos indican pérdida y positivos ganancia de masa. En la Figura 13 se muestra el resultado de esta operación, restringiendo el alcance a la zona del deslizamiento. Para resaltar el resultado, se texturizó el modelo lidar sombreado con la diferencia entre los dos modelos, asignando una escala de color que va de -90 a $90 \mathrm{~m}$. Para ayudar en la interpretación, se calcularon contornos de la diferencia cada $20 \mathrm{~m}$ y posteriormente se suavizó el trazo a través de una generalización. Se pueden apreciar en las partes altas del deslizamiento zonas de pérdida con valor absoluto mayor a $60 \mathrm{~m}$. En la parte central, el bloque deslizado de la cima se muestra circunscrito por el contorno 0 y flaqueado por dos huecos con pérdida de $40 \mathrm{~m}$ que se distinguen en el transecto E. Cuesta abajo del bloque central, se observa la oquedad del orden de $40 \mathrm{~m}$ descrita en el transecto $\mathrm{F}$. En las partes bajas se aprecia la acumulación de masa con valores de hasta $80 \mathrm{~m}$. Nuevamente se puede apreciar las obras del canal de desfogue que atraviesa la zona de acumulación. Hay que recordar que el modelo de antes no incorpora el relieve del fondo del río Grijalva.
3.3. Superficie de deslizamiento, cálculo de su pendiente $\mathrm{y}$ orientación

Se caracterizó la superficie sobre la cual se deslizaron los bloques de lutita y arenisca. Para ello se enmascaró la parte alta del desgajamiento del cerro donde está claramente expuesta la superficie del deslizamiento. La superficie sobre la que se aplicó el análisis esta delineada en color rojo en la Figura 11b. Para esta zona se calculó la pendiente y la orientación del terreno a partir del modelo digital lidar del terreno y de versiones suavizadas de éste para atenuar la variabilidad espacial y ver las tendencias. La zona analizada representa 188154 celdas de $1 \mathrm{~m} \mathrm{x} 1 \mathrm{~m}$ del modelo, es decir 18.8 ha de superficie del deslizamiento, cercano al $22 \%$ del área total afectada. Para obtener versiones suavizadas de la superficie del terreno, se calcularon los valores promedio de elevación en ventanas de $3 \times 3,5 \times 5$ y $9 \times 9$ celdas, también se calculó la mediana en ventanas de $5 \times 5$ y de $11 \times 11$ celdas.

Se hizo la estadística sobre la pendiente y orientación del terreno para la superficie original y sus diferentes versiones suavizadas (Tabla 3 ). Los valores promedio y las medianas, de la pendiente y orientación del terreno, serán 
Tabla 3. Análisis de la pendiente y orientación de la pendiente en la zona expuesta de la superficie de deslizamiento, a partir del modelo digital del terreno lidar y de 6 versiones suavizadas de éste: valor de la mediana de la elevación en ventanas de 5x 5 y $11 \times 11$ celdas y valor promedio de la elevación en ventanas de $3 \times 3,5 \times 5$ y 9x9 celdas. El valor de la pendiente está dado en porcentaje y la orientación de ésta en grados, con el norte igual a cero grados, es decir el azimut.

\begin{tabular}{|c|c|c|c|c|c|c|}
\hline \multicolumn{7}{|c|}{ Estadística de la pendiente y orientación del terreno 6 superficies } \\
\hline & \multirow{2}{*}{$\begin{array}{l}\text { Sin } \\
\text { suavizado }\end{array}$} & \multicolumn{5}{|c|}{ Superficie Suavizada } \\
\hline & & $\begin{array}{c}\text { Mediana } \\
5 \times 5\end{array}$ & $\begin{array}{c}\text { Mediana } \\
11 \times 11\end{array}$ & $\begin{array}{c}\text { Promedio } \\
\mathbf{3 \times 3} \\
\end{array}$ & $\begin{array}{c}\text { Promedio } \\
5 \times 5 \\
\end{array}$ & $\begin{array}{c}\text { Promedio } \\
9 \times 9 \\
\end{array}$ \\
\hline Celdas no nulas & 188154 & 182998 & 175356 & 185577 & 183015 & 177930 \\
\hline Área (hectáreas) & 18.83 & 18.32 & 17.55 & 18.57 & 18.32 & 17.81 \\
\hline \multicolumn{7}{|c|}{$\begin{array}{c}\text { Pendiente del terreno } \\
(\%)\end{array}$} \\
\hline Promedio & 30.20 & 28.26 & 26.01 & 29.14 & 28.07 & 26.43 \\
\hline Mediana & 27.82 & 26.37 & 24.38 & 27.06 & 26.61 & 25.32 \\
\hline Desviación estándar & 15.87 & 15.33 & 14.23 & 14.81 & 13.76 & 12.20 \\
\hline \multicolumn{7}{|c|}{$\begin{array}{c}\text { Orientación de superficie } \\
\text { (azimut) }\end{array}$} \\
\hline Promedio & 234.31 & 238.46 & 243.04 & 236.48 & 238.97 & 242.08 \\
\hline Mediana & 246.09 & 246.78 & 251.01 & 247.50 & 250.32 & 251.72 \\
\hline Desviación estándar & 72.96 & 67.97 & 60.97 & 70.44 & 67.44 & 62.60 \\
\hline
\end{tabular}

representativos de la superficie de falla. La desviación estándar nos estima la dispersión sobre la media. Como era de esperarse, entre más suavizada la superficie, el valor promedio de la pendiente será menor, al igual que la dispersión de la media. La pendiente promedio de la superficie sin suavizado fue de $30.2 \%$ y para las versiones más suavizadas, con ventanas promedio de $9 \mathrm{x} 9 \mathrm{y}$ mediana de $11 \times 11$, fue de 26.43 y $26.01 \%$, respectivamente. Las versiones con suavizado medio (promedio $3 \times 3,5 \times 5$ y mediana $5 \times 5$ ) arrojaron valores entre 28.07 y $29.14 \%$ de pendiente en promedio. La mediana de la pendiente del terreno en sus versiones con y sin suavizado es otro estimador de la tendencia y oscila entre 24.38 y $27.82 \%$.

Con respecto a la orientación de la pendiente, el valor promedio en sus diferentes versiones oscila entre 234.31 y 243.04 grados de azimut. Para el estimador mediana de la orientación de la pendiente, éste arrojó valores de azimut entre 246.01 grados, para el modelo no suavizado, y 251.72 grados, para el modelo con un suavizado a través de promedios en ventanas de 9x9 celdas.

Resumiendo, podríamos decir que la superficie expuesta del deslizamiento tiene una pendiente general cercana al $28 \%$, esto es equivalente a una inclinación de 15.64 grados, con una orientación alrededor de 239 grados de azimut. Hay que recordar que en la interpretación de los lineamientos previos al deslizamiento a través del análisis con visión estereoscópica (Figura 9), se determinó que estos tienen una dirección preferencial de 236 grados de azimut, valor similar a la orientación de la pendiente de la superficie de deslizamiento. No conocemos ni encontramos en la bibliografía información referente a la disposición en el sitio de las lutitas y areniscas de la formación TomAr-Lu. Pensamos que una estructura estratificada con discontinuidades aunada a un basculamiento con orientación similar a la superficie del deslizamiento, pudieran ser circunstancias determinantes en el desencadenamiento del derrumbe. En el mapa de Islas-Tenorio et al. (2005) de la
Figura 7 existe un símbolo estructural a $5 \mathrm{~km}$ al sureste del deslizamiento con orientación y buzamiento $\left(12^{\circ}\right)$ similar a los parámetros encontrados $\left(15.6^{\circ}\right)$.

\subsection{Cálculo del volumen desplazado}

En un primer cálculo grueso del volumen del deslizamiento, podemos considerar sus dimensiones generales y estimarlo. Esto es, con una longitud media de $1150 \mathrm{~m}$, un ancho de $630 \mathrm{~m}$ y una profundidad promedio de $75 \mathrm{~m}$, se obtiene un volumen de 54.3 millones de metros cúbicos $\left(\mathrm{Mm}^{3}\right)$. En un informe (Marengo-Mogollón, 2008) de la Comisión Federal de Electricidad (CFE) y del Colegio de Ingenieros Civiles de México (CICM) se estima un volumen total de $55.4 \mathrm{Mm}^{3}$ desde la superficie de la falla, de los cuales $15.2 \mathrm{Mm}^{3}$ se depositaron sobre el cauce del río y el resto $\left(40.2 \mathrm{Mm}^{3}\right)$ permaneció en la ladera de la margen derecha del río Grijalva. Desconocemos el método que utilizaron para hacerlo.

Asumiendo que la superficie del deslizamiento la podemos modelar como un plano, necesitamos puntos representativos sobre este plano para modelarlo. Con herramientas estándar de SIG se muestreó 11 posiciones en 3D (x, y, z) de la superficie de deslizamiento del modelo de terreno lidar. Éstas se indican en color rojo en la Figura 11b. El objetivo es que a partir de puntos representativos de la superficie expuesta, se ajuste un plano por el método de mínimos cuadrados descrito en la sección 2.3 de la metodología. El plano se evalúa sobre toda la extensión del deslizamiento. Desde la cima del cerro hasta la orilla del río. La extensión se indica con un polígono blanco en la Figura 11a, donde también se muestran ejemplos de puntos del plano ocluidos por el derrumbe (color verde). Los coeficientes obtenidos en la solución se presentan en la Tabla 4 junto con las coordenadas de los puntos utilizados en el sistema de ecuaciones. El error cuadrático medio 
Tabla 4. Coordenadas $\mathrm{x}, \mathrm{y}, \mathrm{z}$ de los puntos representativos sobre la superficie expuesta del deslizamiento. Su ubicación se indica con puntos rojos en la Figura 11. La componente $Z$ se obtuvo muestreando el modelo del terreno lidar. Los coeficientes para la Ecuación (3) fueron obtenidos en la solución por mínimos cuadrados.

\begin{tabular}{cccc}
\hline Punto & $\mathbf{X}$ (UTM15) & Y (UTM15) & $\mathbf{Z}(\mathbf{m})$ \\
\hline 1 & 459770.8 & 1920824.6 & 174.74 \\
2 & 459780.5 & 1920897.5 & 179.03 \\
3 & 459812.1 & 1920817.3 & 177.22 \\
4 & 460108.8 & 1920824.6 & 228.78 \\
5 & 460157.5 & 1920790.5 & 239.70 \\
6 & 460133.2 & 1920739.5 & 234.07 \\
7 & 459953.2 & 1920542.5 & 198.03 \\
8 & 459931.3 & 1920578.9 & 195.64 \\
9 & 459977.5 & 1920608.1 & 200.92 \\
10 & 459943.5 & 1920642.2 & 194.04 \\
11 & 459831.6 & 1920892.7 & 189.92 \\
\hline
\end{tabular}

\begin{tabular}{cc}
\hline Coeficiente & Valor \\
\hline e & 0.168681184 \\
$\mathrm{f}$ & 0.031887398 \\
$\mathrm{~g}$ & -138630.5007 \\
\hline
\end{tabular}

(RMS) del ajuste fue de $7.63 \mathrm{~m}$. La superficie modelada, se utilizó como base para el cálculo del volumen que se ubica entre la superficie de deslizamiento y el modelo de elevación previo al derrumbe, lo cual nos arrojó un volumen de $47.4 \mathrm{Mm}^{3}$. Este cálculo puede hacerse a través de una resta o diferencia entre el modelo de elevación de antes y la superficie del plano calculado, restringiendo la extensión al área afectada. Esta es una operación estándar de cualquier SIG o programa de teledetección y su esquema se muestra en la Figura 14.

\section{Discusión}

Según Mendoza-López et al. (2002) existe una relación entre la inestabilidad de laderas y la intensidad de la lluvia. Los deslizamientos en su gran mayoría son inducidos por lluvias cortas de intensidad alta, y estos ocurren prácticamente al mismo tiempo que el pico de la lluvia horaria. En el caso del deslizamiento que obstruyó el cauce del río Grijalva, las lluvias fueron muy intensas pero no coincidieron en el tiempo con la ocurrencia del fenómeno. No se contó con información de intensidad de la lluvia de estaciones dentro de la cuenca de la presa Peñitas, sin embargo, de la Tabla 1 se advierte que la precipitación máxima por día disminuyó desde el pico de $403 \mathrm{~mm}$ para el 28 de octubre hasta $6.2 \mathrm{~mm}$ el 4 de noviembre, día del deslizamiento. Hay un periodo de 7 días entre el pico de precipitación y la fecha del deslizamiento. De la estación CECECH se obtuvo la intensidad de la lluvia y anteriormente se señaló que ésta seguía (Figura 4) las tendencias de precipitación máxima en la cuenca Peñitas (Figura 3 y Tabla 1) y del gasto que arribaba a la presa (Figura 5). Se puede distinguir que el pico de la lluvia y el deslizamiento no ocurrieron al mismo tiempo. A partir del 2 noviembre no se registró precipitación en la estación CECECH previa al deslizamiento y para las estaciones de la cuenca Peñitas, la precipitación promedio se redujo sustancialmente. Creemos que los eventos de precipitación extrema ocurridos del 23 al 30 de octubre no fueron la única causa del deslizamiento de ladera; existe un lapso de 5 días entre la terminación del último evento y el deslizamiento.

En el curso sinuoso de un río, la corriente es más rápida y erosiva en las curvas exteriores de su cauce. El deslizamiento ocurrió en la margen derecha de una curva exterior muy cerrada del río Grijalva (Figura 7), $16 \mathrm{~km}$ aguas arriba de la presa Peñitas. Días previos al deslizamiento, el caudal del río Grijalva que arribaba a la presa Peñitas tuvo varios ascensos abruptos, alcanzando el 29 de octubre los $5000 \mathrm{~m}^{3} / \mathrm{s}$, esto es 5 días previos al evento. Pensamos que el gran caudal tuvo un efecto al concentrar su fuerza erosiva en la base del derrumbe por venir, así como el aumento paulatino del nivel general del agua (Figura 5). Consideramos que este efecto erosivo pudo haber debilitado la base del cerro de la Pera, contribuyendo al desbalance de fuerzas que originaron el deslizamiento, pero al igual que los otros factores, con un efecto retardado y complementario.

Los factores que se conjugaron para inducirlo, los podemos agregar en dos grupos funcionales: los intrínsecos del terreno, que son preexistentes y latentes, y los factores extrínsecos, que son circunstanciales. Mientras los primeros son fijos y constantes, los segundos fueron los catalizadores del deslizamiento. Entre los intrínsecos tenemos:

- La preexistencia de fallas y alineamientos a lo largo de los contactos de deslizamiento, los cuales favorecieron el colapso. Estas pueden ser claramente distinguidas en las imágenes previas. La fotointerpretación de los pares estereoscópicos sintéticos las hace evidentes.

- La deforestación a lo largo de algunos de los ejes del deslizamiento pudo haber favorecido la erosión y debilitamiento en la cohesión del material.

- La presencia de material sedimentario (lutitas y areniscas) poco consolidado con estratificación laminada que favoreció la caída del bloque. La posible presencia de discontinuidades entre estratos.

Entre los factores extrínsecos desencadenantes tenemos:

- Un suelo saturado por la secuencia de eventos de precipitación extrema que aumentó la presión de poro, disminuyó los esfuerzos efectivos y desbalanceó el equilibrio de las componentes a lo largo de los planos de debilidad.

- El aumento en el caudal del río Grijalva, generado por las precipitaciones extremas y el incremento en las escorrentías en la cuenca media, erosionó la base del cerro en las orillas del río, aunándose al desbalance de fuerzas. 

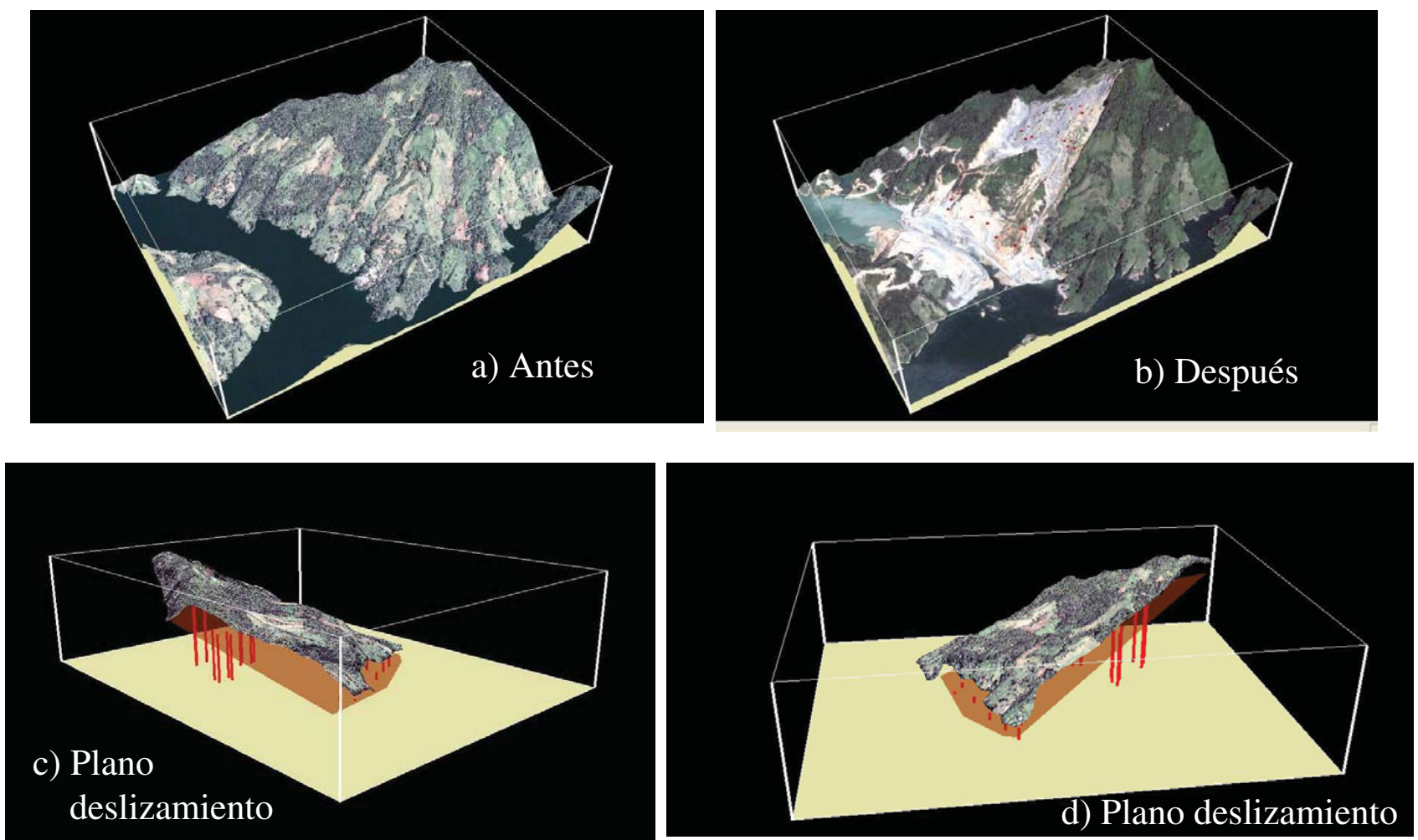

Figura 14. Modelos de elevación texturizados con imágenes satelitales. Perspectivas de antes (a) y después (b) del deslizamiento generadas con los insumos teledetectados de la Tabla 2. Perspectivas de la superficie de deslizamiento modelada (c y d) con la sobreposición del modelo de elevación previo al deslizamiento (texturizado con imagen satelital). La diferencia entre estas dos superficies se utilizó para estimar el volumen del deslizamiento.

- No hay evidencia de algún evento sísmico cercano inmediatamente antes del deslizamiento, sin embargo, no descartamos que el evento del 30 de octubre de magnitud 4.5 localizado a $\sim 20 \mathrm{~km}$ del derrumbe haya tenido influencia indirecta en combinación con el pico de precipitación.

Con respecto a la velocidad de los bloques removidos, podemos inferir una velocidad promedio cercana a los $17.5 \mathrm{~m} / \mathrm{s}$. Esta cifra surge de la duración de 40 segundos del registro sísmico del deslizamiento reportado para la estación sismológica a $16 \mathrm{~km}$ de distancia y de la distancia recorrida de los bloques obtenida de los modelos de elevación cercana a los $700 \mathrm{~m}$ (Figura 12b). Ésta es la distancia desde la cima del cerro a la parte media del deslizamiento donde se detuvieron los bloques. Como complemento a esta investigación, se está trabajando en el análisis de la traza sísmica previa y durante el deslizamiento registrada en la estación del volcán Chichonal. Esto con el propósito de explorar la microsismicidad previa al deslizamiento, activad no reportada en los catálogos regionales (SSN y NEIC) y que pudo haber incidido. Asimismo se trabaja en analizar la señal y energía liberada por el derrumbe.

\section{Conclusiones}

El deslizamiento de ladera del 4 de noviembre de 2007, que interrumpió por 44 días el flujo natural del río Grijalva, no lo podemos atribuir a una sóla causa. Consideramos que fue una suma de factores, donde la intensa precipitación de días antes tuvo una importante contribución, al lubricar el plano de debilidad en la superficie de ruptura y por generar un extraordinario caudal que erosionó la base del cerro. Tampoco se puede descartar el efecto del sismo de magnitud 4.5 a $20 \mathrm{~km}$ de distancia 5 días antes. Sin los insumos de teledetección, en combinación con herramientas de SIG y percepción remota, sería muy difícil dimensionar y visualizar fenómenos naturales de este tipo. La generación de estereopares sintéticos que, con el apoyo de un estereoscopio, habilitaron la fotointerpretación en 3 dimensiones de los lineamientos previos al deslizamiento, así como el posterior dimensionamiento del fenómeno. A través de insumos teledetectados y herramientas de SIG y teledetección se pueden hacer muchas inferencias y mediciones sobre fenómenos como éste sin haber visitado el lugar. Sin embargo, la visita al campo proporciona aspectos clave insustituibles por la teledetección. La medición in situ del rumbo y echado de los estratos de lutita y arenisca, hubiera confirmado o rechazado algunas de las especulaciones planteadas.

Los levantamientos lidar aerotransportados y terrestres, así como la fotogrametría satelital de alta resolución espacial, son tecnologías emergentes que miden con sorprendente detalle la sinuosidad del relieve. El modelo del terreno lidar posterior al deslizamiento fue un insumo de 
mucha utilidad que, acompañado de herramientas de SIG, permitió el cálculo de perfiles transversales a lo largo de éste, generación de contornos, estimación de la pendiente y orientación de la superficie de ruptura, así como el volumen de roca desplazado. El acceso a librerías de imágenes, como el caso de Digital Globe, fue también de mucho beneficio. Permitió descargar en línea escenas previas y posteriores al deslizamiento, que están disponibles en el acervo sin necesidad de adquirirlas. La suscripción a estos servicios puede ser conveniente para diversas entidades de gobierno y del sector privado.

Es de suma importancia la rápida adquisición y procesado de observaciones ópticas y de microondas de una zona afectada por desastres naturales a fin de monitorear, medir, estimar daños y tomar decisiones en eventos donde el tiempo es crítico para salvar vidas, canalizar ayuda, orientar esfuerzos de remediación y reconstrucción. Por la cantidad de información que generan los nuevos sensores como el lidar, se presentan nuevos retos en el procesado, interpretación y almacenamiento de los datos; se requiere de nuevos paradigmas que permitan dar respuesta rápida a las necesidades. Estar preparados nos permitirá enfrentar mejor los eventos extremos inducidos por el cambio climático, que se prevé que aumenten en frecuencia e intensidad (IPCC, 2007).

\section{Agradecimientos}

Al INEGI por facilitar el acceso a los modelos digitales del terreno y superficie de la zona del deslizamiento, material que además de usarse en este trabajo, se emplea como material docente en los cursos de postgrado del CICESE. Especial agradecimiento a Enrique Jesús Ordaz López, Carlos Guerrero Elemen, Juan Javier Durón Díaz, Virginia Abrín Batule y Daniel Flores García.

Queremos agradecer también a Digital Globe, ya que a través de su distribuidor en México GTT Imaging de Guadalajara, facilitó el acceso a su librería de imágenes por medio del servicio Image Connect, en especial a Elena Rodríguez y a Sedna Monter. A Ramón Arrowsmith y Chris Crosby, las organizaciones geongrid.org y opentopography.org que nos introdujeron a la tecnología lidar en sus cursos de verano de ciber-infraestructura para geocientíficos. A Ignacio Méndez y Antonio Mendoza del departamento de Sismología del CICESE. Al meteorólogo del CICESE Alfonso Higareda por la gestión de los datos de precipitación de la CNA. Al Ing. Enrique Guevara Ortíz de CENAPRED, por facilitar las trazas sísmicas y características la estación del volcán Chichonal. A José Frez por sus observaciones y sugerencias en el cálculo del plano de falla por mínimos cuadrados. A los revisores del artículo Aline Concha Dimas y Pere Oller Figueras.

\section{Bibliografía}

Alcántara-Ayala, I., Domínguez-Morales, L., 2008, The San Juan de Grijalva Catastrophic Landslide, Chiapas, Mexico: Lessons Learnt (en línea), en Web Proceedings of The First World Landslide Forum: Tokio, Japón, United Nations University, ICL-International Consortium on Landslides/ISDR-United Nations International Strategy for Disaster Reductions, 96-99. disponible en http:// www.iclhq.org/WLFweb/parallel_sessions.pdf, consultada el 26 de febrero de 2011.

Batson, R.M., Edwards, K., Eliason, E.M. 1976, Synthetic stereo and Landsat pictures: Photogrammetric Engineering \& Remote Sensing, 42, 1279-1284.

CAH-SRM, Comisión de Asuntos Hidráulicos, Senado de la República Mexicana, Informe de las Inundaciones de 2007 en el Estado de Tabasco, Diagnóstico Preliminar, 2008, (en línea): http://www. imta.gob.mx/gaceta/anteriores/g12-04-2008/informe-tabasco.pdf, consultado 26 de septiembre 2009.

Dadson, S.J., Hovius, N., Chen, H., Dade, W.B., Lin, J.C., Hsu, M.L., Lin, C.W., Horng, M.J., Chen, T.C., Milliman, J., Stark, C.P., 2004, Earthquake-triggered increase in sediment delivery from an active mountain belt: Geology, 32, 733-736.

Del Solar, R., 2007, Tapón del Grijalva es nueva amenaza (en línea): Centro Virtual de Información del Agua, disponible en http://www.agua. org.mx/index.php?option $=$ com content $\&$ view $=$ article $\&$ id $=3416: t$ apon-del-grijalva-es-nueva-amenaza $\&$ catid $=61 \&$ Itemid $=100010$, consultado el 26 de febrero de 2011.

DigitalGlobe, 2003, Imagen Quickbird (imagen satelital): Longmont, Colorado, tomada el 20 de febrero de 2003, disponible en $<$ www. digitalglobe.com/index.php/48/Products?product_id=19>, descargada el 26 de septiembre de 2009.

DigitalGlobe, 2008, Imagen Quickbird (imagen satelital): Longmont, Colorado, tomada el 18 de febrero de 2008, disponible en <www. digitalglobe.com/index.php/48/Products?product_id=19>, descargada el 26 de septiembre de 2009.

Environmental Systems Research Institute (ESRI), 2009, ArcGIS version 9.3., Spatial Analyst Extension, Hydrologic Modeling Toolbox (programa informático): Redlands, California, Environmental Systems Research Institute, CD-ROM.

Farr, T.G., Kobrick, M., 2000, Shuttle Radar Topography Mission produces a wealth of data: American Geophysical Union Eos, 81, 583-585.

Guevara-Ortiz E., 2010, Centro Nacional de Prevención de Desastres (CENAPRED), comunicación personal.

Harp, E.L., Jibson, R.W., 1996. Landslides triggered by the 1994 Northridge, California, Earthquake: Bulletin of the Seismological Society of America, 86, 319-332.

Instituto Nacional de Estadística, Geografía e Informática (INEGI), 2003, Continuo de elevaciones de México (CEM) (en línea): Aguascalientes, Aguascalientes, México, disponible en <http://mapserver. inegi.org.mx/DescargaMDEWeb/?s=geo\&c=977>, consultado el 26 de febrero de 2011.

Instituto Nacional de Estadística, Geografía e Informática (INEGI), 2006, II Conteo de Población y Vivienda 2005. Principales resultados por localidad: Aguascalientes, Aguascalientes, México, http:// www.inegi.org.mx/est/contenidos/espanol/proyectos/coesme/ programas/ficha.asp?cve_prod $=542 \& \mathrm{c}=10386$, consultado el 26 de febrero de 2011.

Instituto Nacional de Estadística Geografía e Informática (INEGI), 2008, Modelo digital de elevación de alta resolución Lidar, Tipo TERRENO, GRJ_MDT00XX (datos y metadatos): Aguascalientes, Aguascalientes, México.

IPCC (Intergovernmental Panel on Climate Change) 2007, Climate Change 2007. Synthesis Report. Contribution of the Working Groups I, II, and III to the Fourth Assessment Report of the Intergovernmental Panel on Climate Change, Pachauri, R.K., Reisinger, A., (eds.), 104 p., Genova, Suiza.

Islas-Tenorio, J.J., Ramirez-García, M.G., Ávilez-Gómez, A., MorenoRuiz, J.P., Wingartz-Carranza, J.A., Mendieta-Flores, J.L, 2005, 
Carta geológico-minera, Villahermosa E15-8, escala 1:250 000: México, Servicio Geológico Mexicano, Primera Edición, 1 mapa con texto.

Kowalik, W.S., 1993, Artificial stereo remote sensing images in geologic interpretation en Environmental Research Institute of Michigan, Proceedings of the Ninth Thematic Conference on Geologic Remote Sensing: Pasadena, California, $41 \mathrm{p}$.

Li, D., 2009, Remote sensing in the Wenchuan earthquake: Photogrammetric Engineering \& Remote Sensing, 75, 506-509.

Marengo-Mogollón, H., 2008. Deslizamiento de tierra y roca que obstruyó el río Grijalva: Comisión Federal de Electricidad, Colegio de Ingenieros Civiles de México, disponible en http://ingenet.com. $\mathrm{mx} /$ noticias/?p=2841, consultado el 26 de septiembre de 2009 .

Martines, L.E., 2007, El "tapón" salvó a Tabasco, Juan de Grijalva a la expectativa: El Heraldo de Tabasco, 24 de noviembre de 2007, disponible en <www.oem.com.mx/elheraldodetabasco/notas/ n501481.htm>, consultado 26 de septiembre de 2009.

Mendoza-López, M.J., Domínguez-Morales, L., Noriega-Rioja, I., Guevara-Ortiz, E., 2002, Monitoreo de laderas con fines de evaluación y alertamiento: Cd. de México, Centro Nacional de Prevención de Desastres (CENAPRED), $77 \mathrm{p}$.

Rubio-Gutiérrez, H., Triana-Ramírez, C., 2006, Gestión integrada de crecientes caso de estudio México: río Grijalva (en línea): Ginebra, Suiza, Organización Meteorológica Mundial, publicado septiembre de 2006, disponible en <www.apfm.info/pdf/case_studies/ cs_mexico.pdf $>$, consultado 26 de septiembre de 2009

Sabins, F.F., 1987, Remote Sensing Principles and Image Interpretation: Nueva York, W.H. Freeman, $447 \mathrm{p}$.

United States Geological Survey (USGS), 2004, Landslide Types and Processes, Fact sheet 2004-3072 (en línea): Reston, Virginia, United States Geological Survey, publicado julio de 2004, disponible en $<$ http://pubs.usgs.gov/fs/2004/3072/fs-2004-3072.html>, consultado 26 de septiembre de 2009.

Zhang, Z., Zhang, Y., Ke, T., Guo, D., 2009, Photogrammetry for first response in Wenchuan earthquake: Photogrammetric Engineering \& Remote Sensing, 75, 510-513.

Manuscrito recibido: Octubre 12, 2009

Manuscrito corregido recibido: Enero 3, 2011

Manuscrito aceptado: Enero 10, 2011 